\title{
The Role of Extracellular Matrix in Myelination and Oligodendrogenesis of the Central Nervous System
}

\author{
Zabihollah Khaksar ${ }^{1}$, Hassan Morovvati², Hamid Reza Moradi², Sajad Sahab Negah ${ }^{3,4 *}$ \\ ${ }^{1}$ Department of Basic Sciences, Faculty of Veterinary Medicine, Shiraz University, Shiraz, Iran \\ ${ }^{2}$ Department of Basic Sciences, Faculty of Veterinary Medicine, University of Tehran, Tehran, Iran \\ ${ }^{3}$ Department of Neuroscience, Mashhad University of Medical Sciences, Mashhad, Iran \\ ${ }^{4}$ Shefa Neuroscience Research Center, Khatam Alanbia Hospital, Tehran, Iran
}

\begin{tabular}{lll}
\hline & Article Info: & \\
\hline Received: 21 Jul 2018 & Revised: 11 Nov 2018 & Accepted: 21 Jan 2019
\end{tabular}

\section{A BSTRACT}

Introduction: Myelin is produced by oligodendrocytes in the central nervous system (CNS). Extracellular matrix (ECM) plays a key role in the regulation and coordination between oligodendrocytes, axons, and myelin. The development and survival of the CNS depend on the precise function of ECM components, including proteins, glycoproteins, glycosaminoglycans and proteoglycans. Structurally, ECM provides anchor points for nerve cells and facilitates the organization of these cells in different CNS areas. Chemically, ECM is the source of a variety of molecular signals that cause the growth, differentiation, and survival of the neuronal cells. In this study, we discuss the role of the components, factors, and signaling pathways of in ECM, including laminin, collagen, fibronectin, neurotrophic factors, neuregulin, tenascin, transferrin, semaphorin and chondroitin sulfate on regulation of myelination in the CNS. Exact coordination of positive and negative regulators of ECM for myelination is important in the production and maintenance of the correct amount of myelin to optimize the function of the CNS. Suitable ECM mimics in 3D culture media for myelination or remyelination can play an important role in improving the therapeutic strategies in myelin sheath degenerative diseases. Conclusions: In this review, we discuss how ECM regulates the CNS myelination and oligodendrogenesis. We also review the role of ECM in demyelinating diseases and discuss 3D mediums for the models of neurodegenerative diseases.

\section{Key words:}

1. Extracellular Matrix

2. Central Nervous

System

3. Myelin Sheath

*Corresponding Author: Sajad Sahab Negah

E-mail: sahabnegahs@mums.ac.ir 


\title{
نقش ماتريكس خارج سلولى در ميلينسازى و اليگودندروزنز سيستم اعصاب مركزى
}

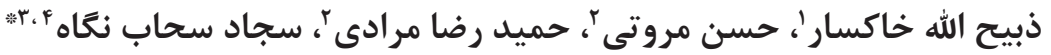 \\ 'امروه علوم پايه، دانشكده داميزشكى، دانشكاه شيراز، شيراز، ايران

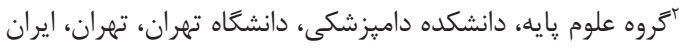

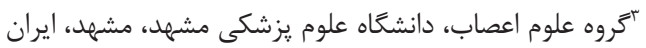

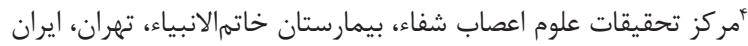

تاريخ دريافت: ·r تير Vqr I اطلاعات مقاله:

كليد وازهها:

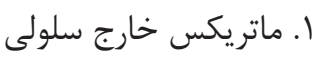

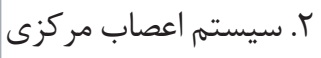
r.
مقدمه: ميلين توسط سلولهاى اليگودندروسيت در سيستم اعصاب مركزى توليد مى شود. ماتريكس خارج

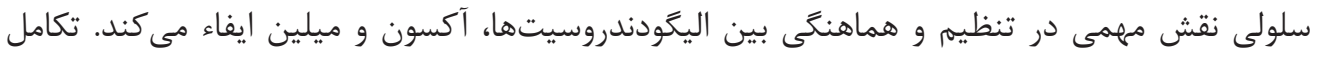

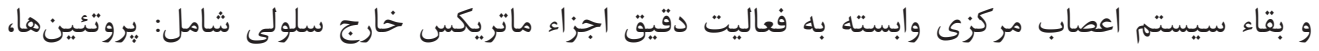

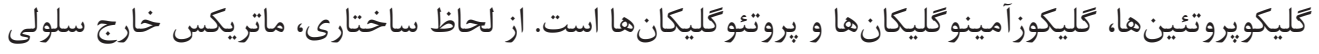

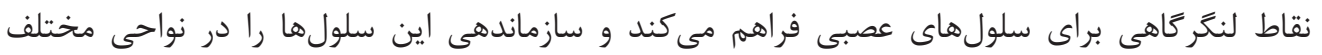

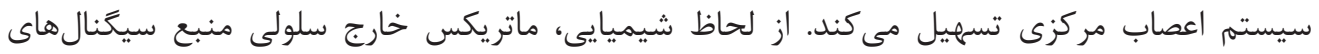

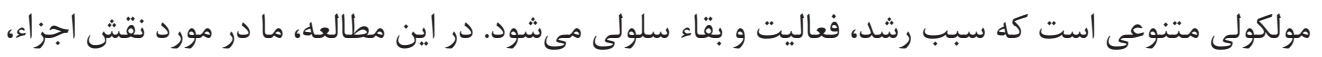

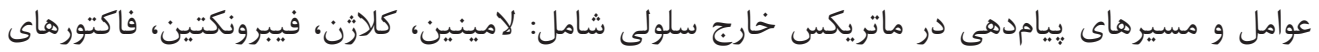

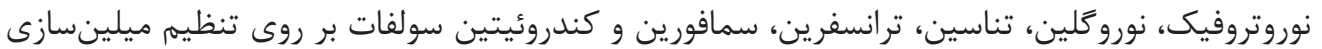

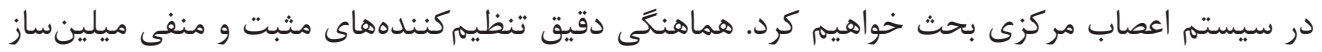

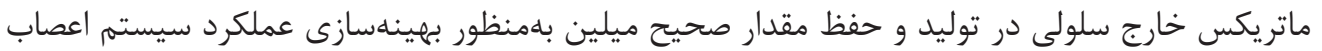
مركزى مهرم است. با شبيهسازى ماتريكس خارج

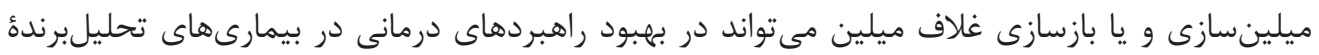

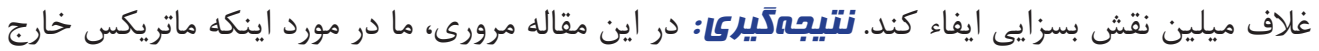

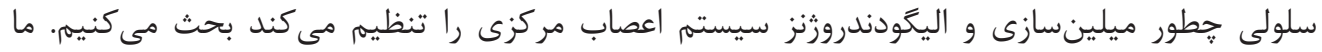

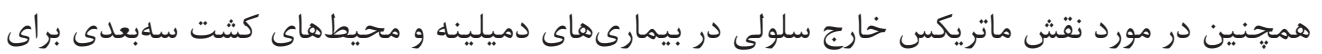

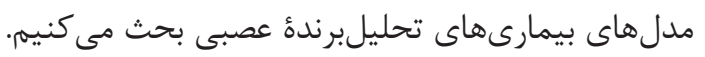

" نويسنده مسئول: سجاد سحاب نحَاه آدرس الكترونيكى: sahabnegahs@mums.ac.ir 


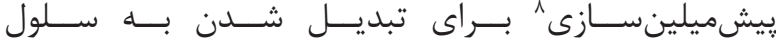

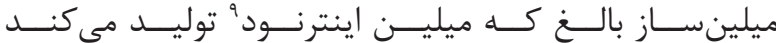

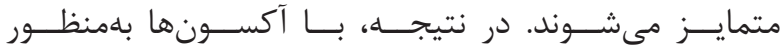

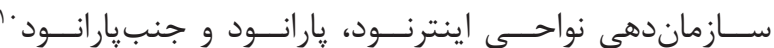

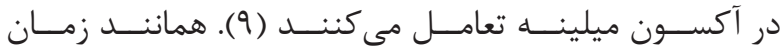

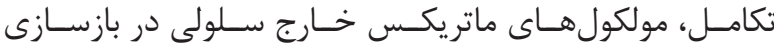

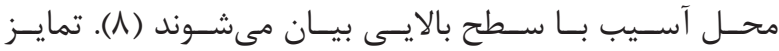

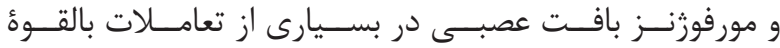

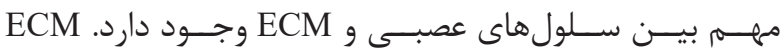

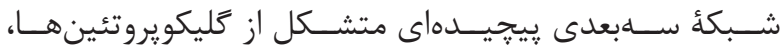

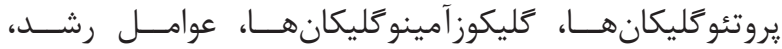

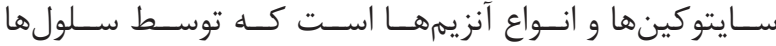

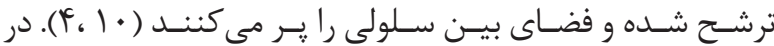

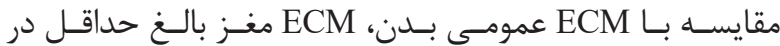

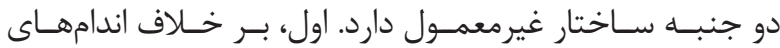

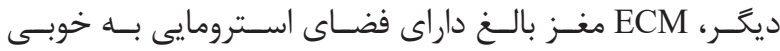

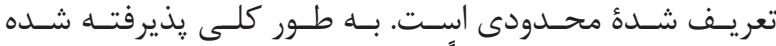

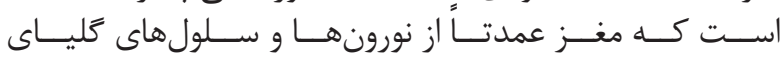

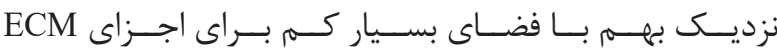

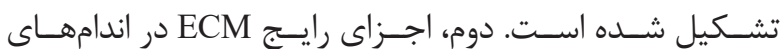

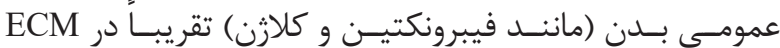

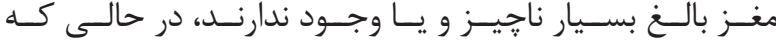

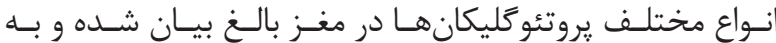

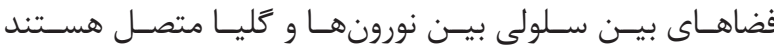

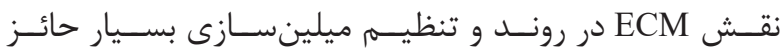

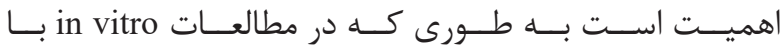

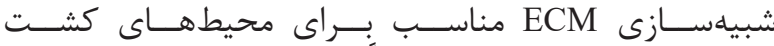

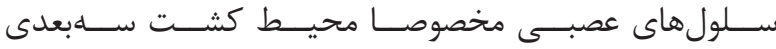

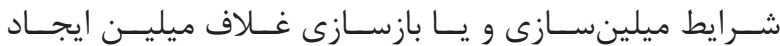

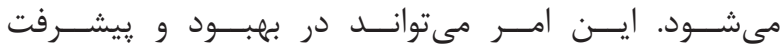

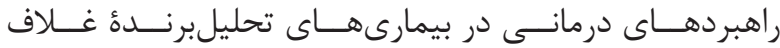

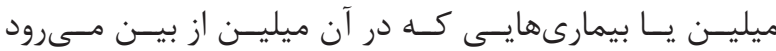

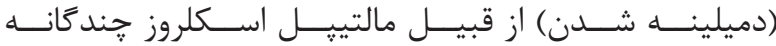

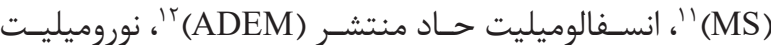

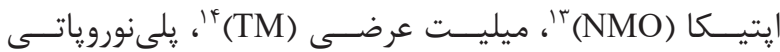

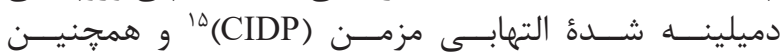

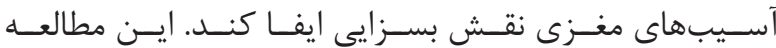

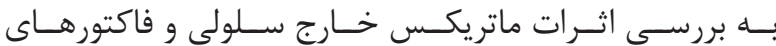

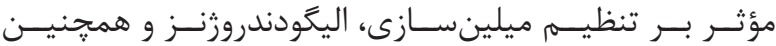

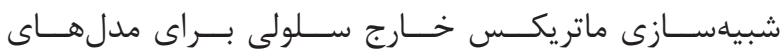

$$
\text { بيمارىهــاى دميلينــه مى خــــردازد. }
$$

\footnotetext{
${ }^{1}$ Myelination

${ }^{2}$ Virchow

${ }^{3}$ Central nervous system

${ }^{4}$ Extracellular matrix

${ }^{5}$ Oligodendrocyte precursor cells

${ }^{6}$ Neuronal-glial antigen 2

${ }^{7}$ Platelet-derived growth factor

${ }^{8}$ Premyelinating stage
}

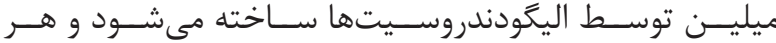

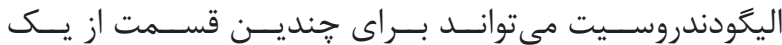

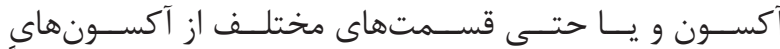

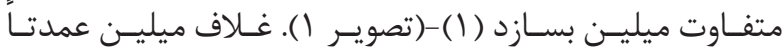

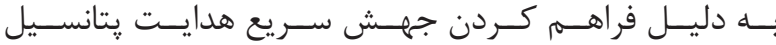

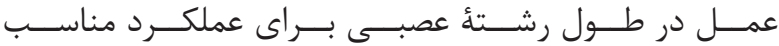

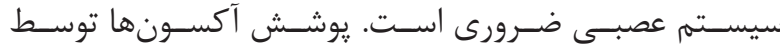

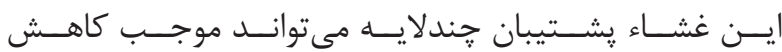

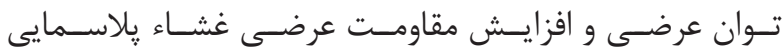

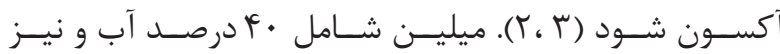

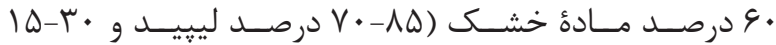

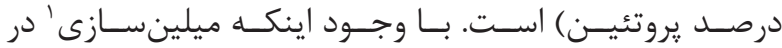

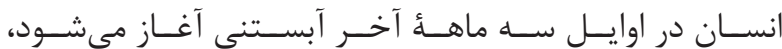

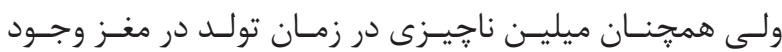

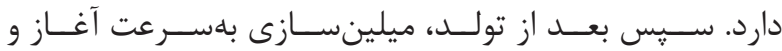

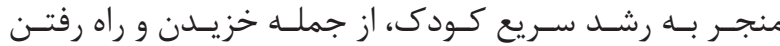

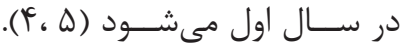

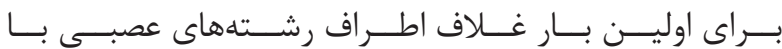

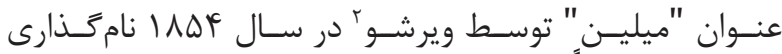

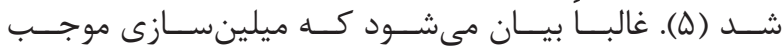

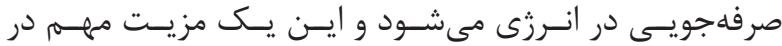

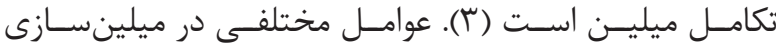

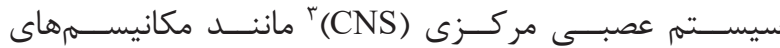

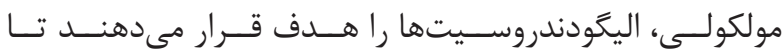

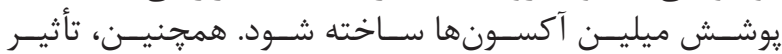

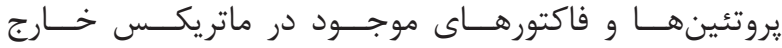

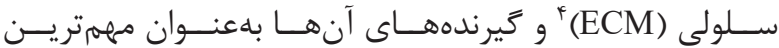

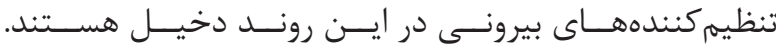

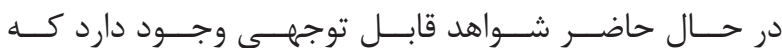

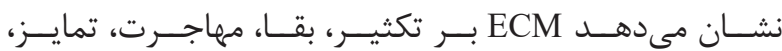

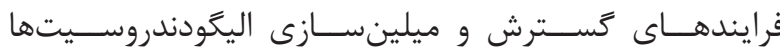

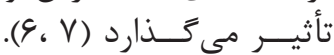

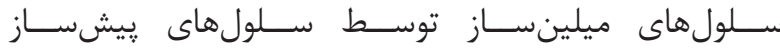

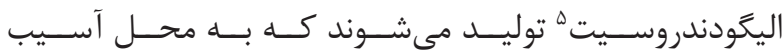

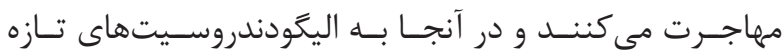

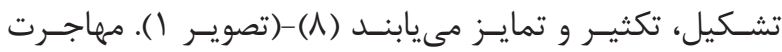

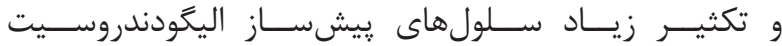

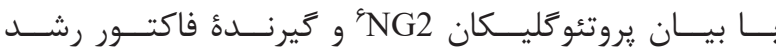

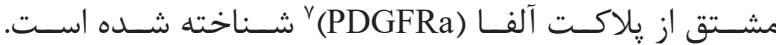

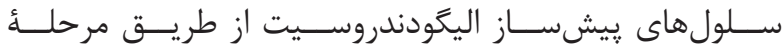

${ }^{9}$ Internode

${ }^{10}$ Juxtaparanode

${ }^{11}$ Multiple sclerosis

${ }^{12}$ Acute disseminated encephalomyelitis

${ }^{13}$ Neuromyelitis optica

${ }^{14}$ Transverse myelitis

${ }^{15}$ Chronic inflammatory demyelinating polyneuropathy 


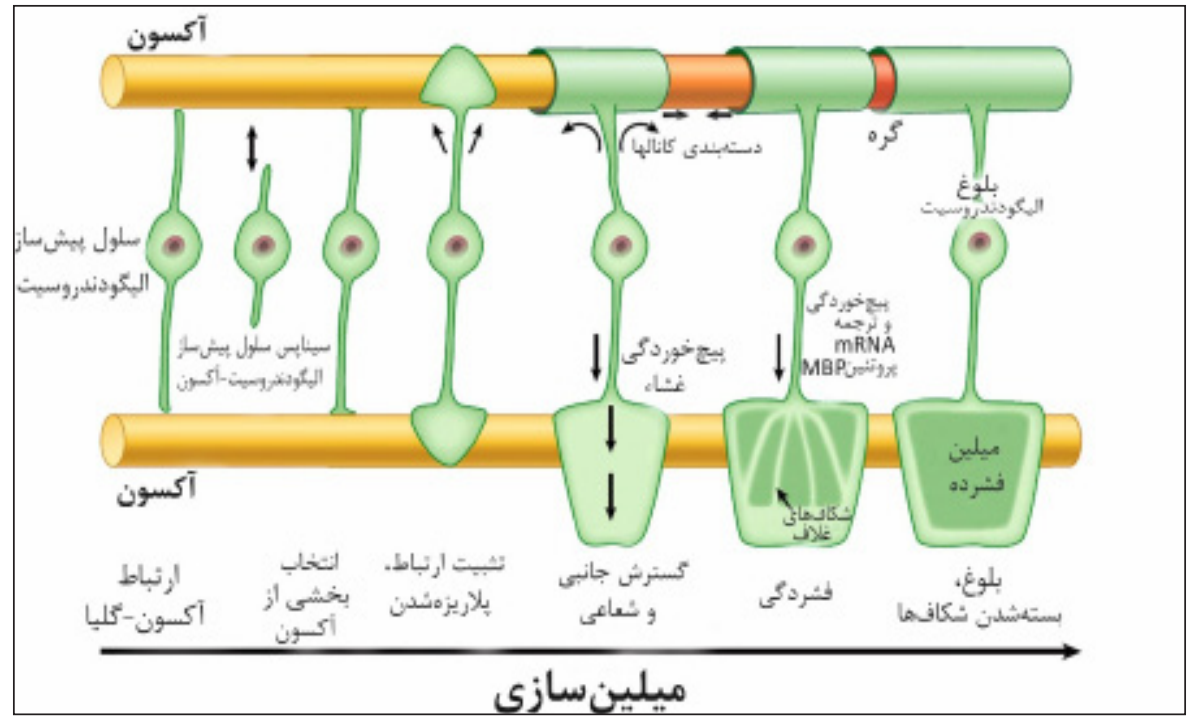

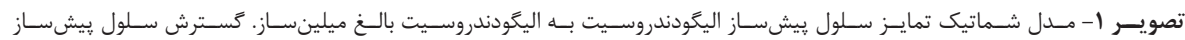

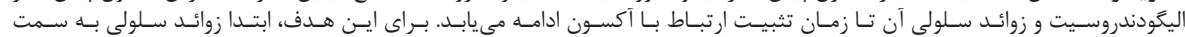

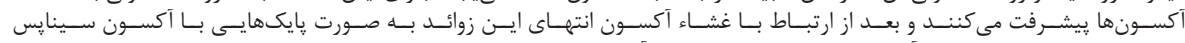

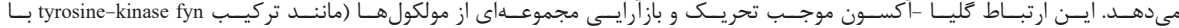

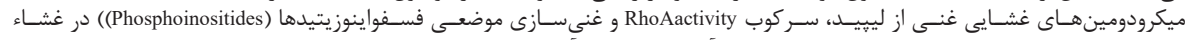

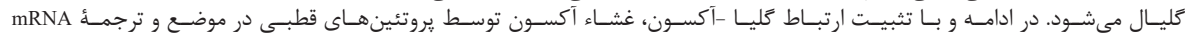

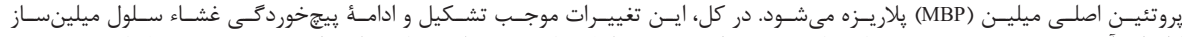

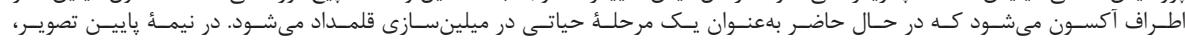

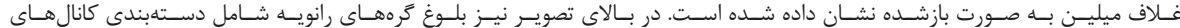

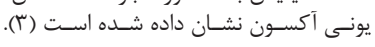

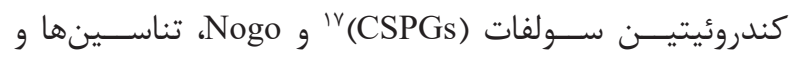

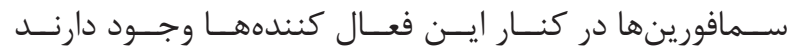

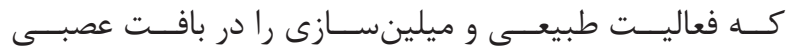

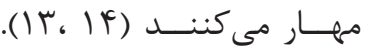

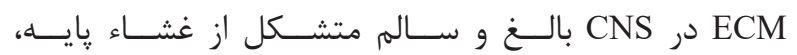

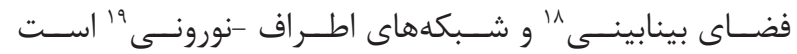

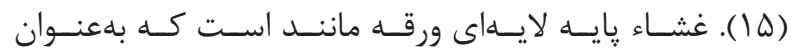

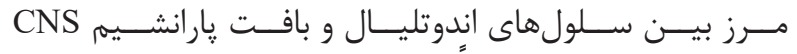

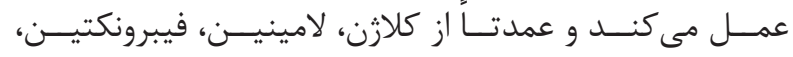

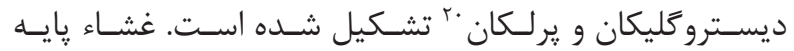

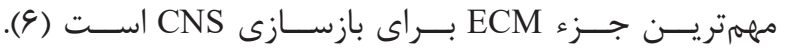

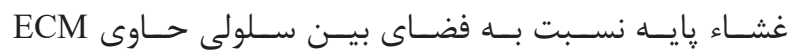

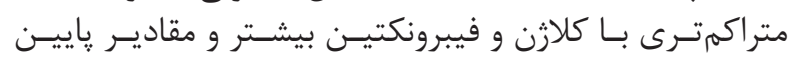

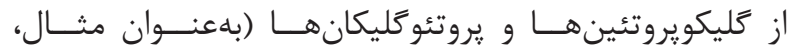

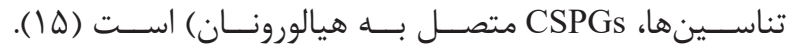

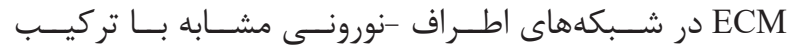

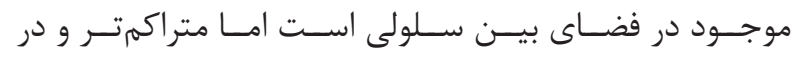

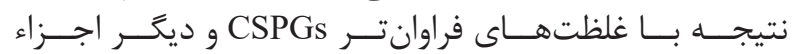

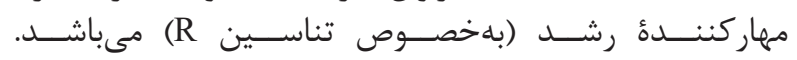

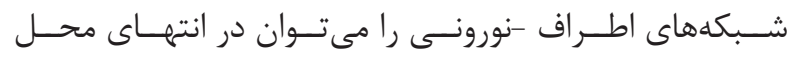

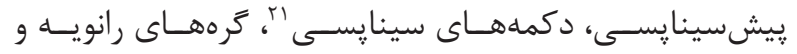

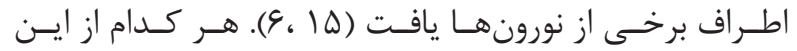

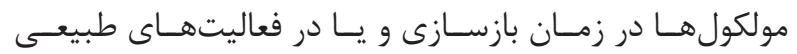

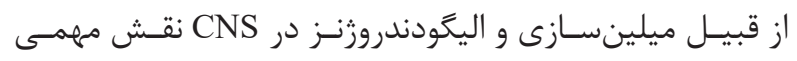

\footnotetext{
${ }^{16}$ Neurogenesis

${ }^{17}$ Chondroitin sulphate proteoglycans

${ }^{18}$ Interstitial space
}

نســبت قابـل توجهـى از سيسـتم عصبـى مركـزى را

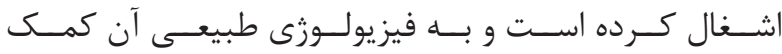

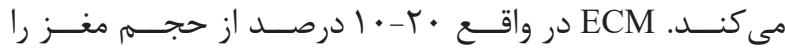

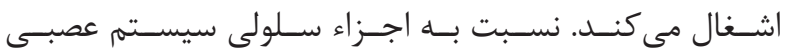

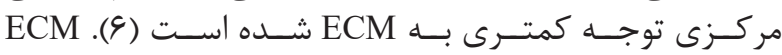

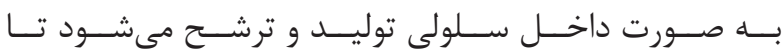

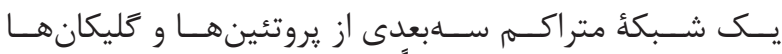

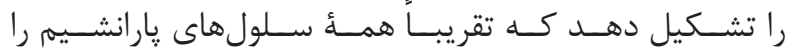

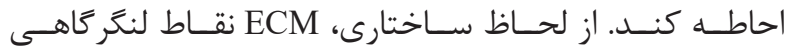

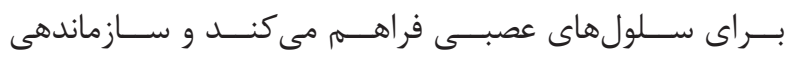

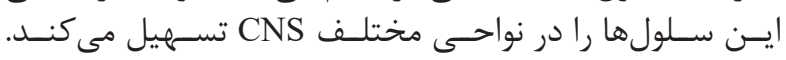

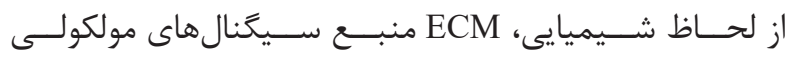

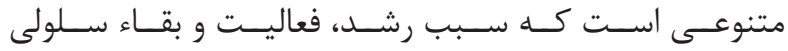

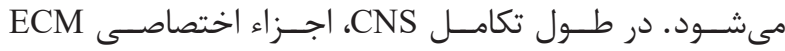

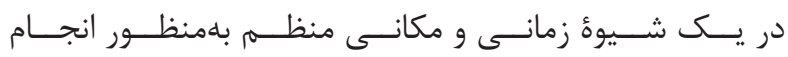

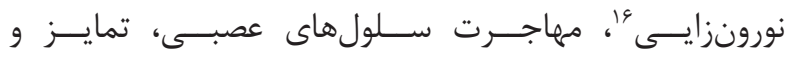

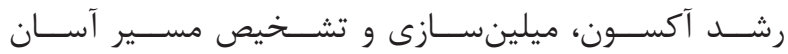

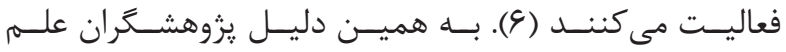

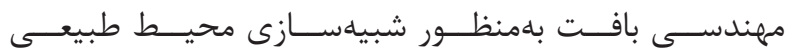

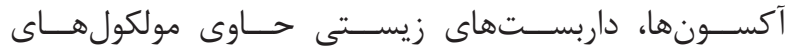

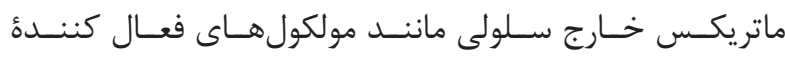

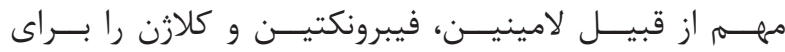

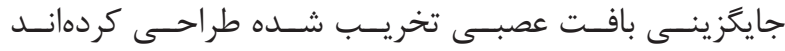

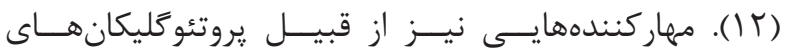

\footnotetext{
${ }^{19}$ Perineuronal nets

${ }^{20}$ Perlecan

${ }^{21}$ Synaptic boutons
} 


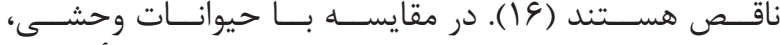

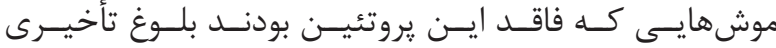

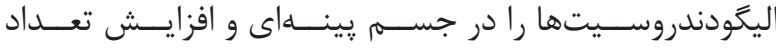

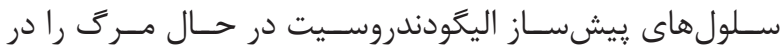

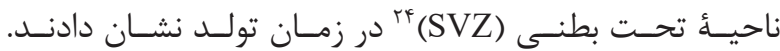

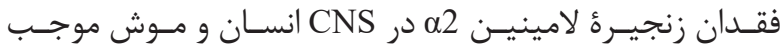

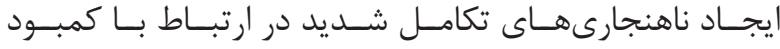

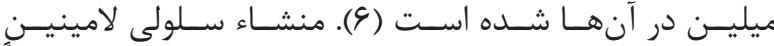

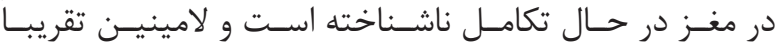

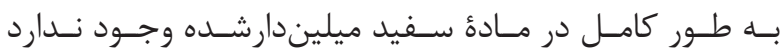

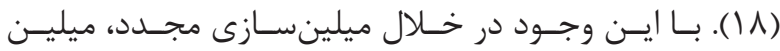

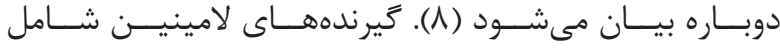

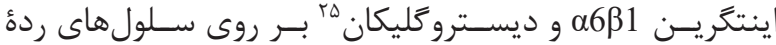

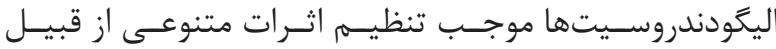

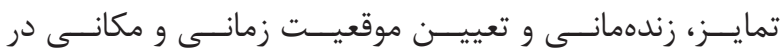

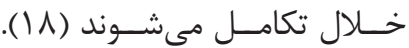

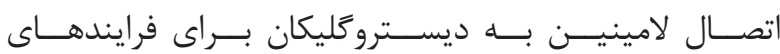

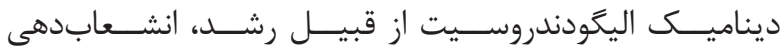

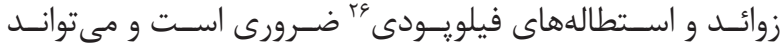

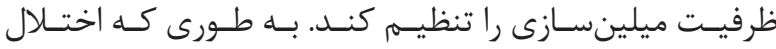

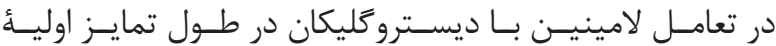

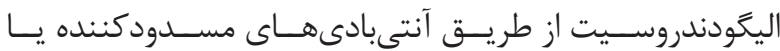

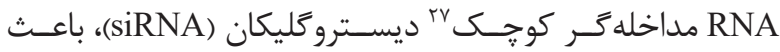

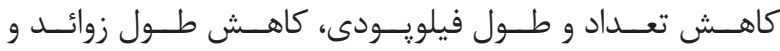

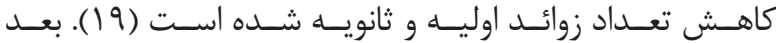

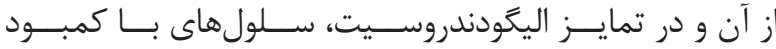

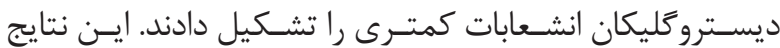

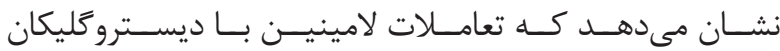

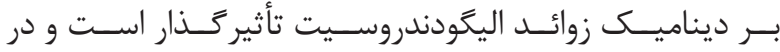

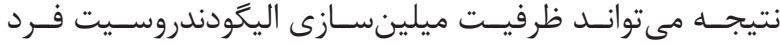

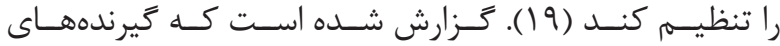

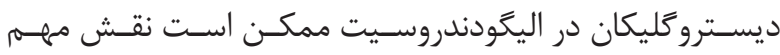

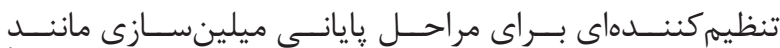

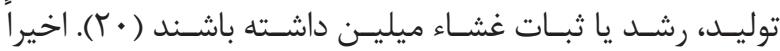

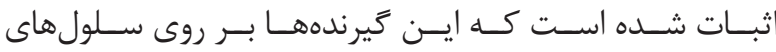

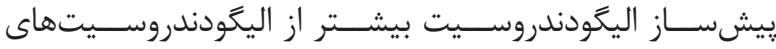

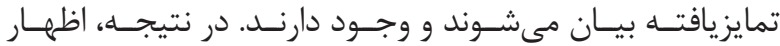

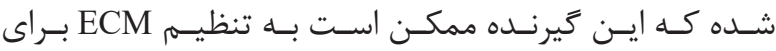

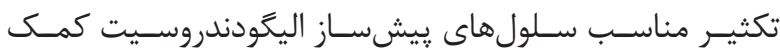

كنــد (T)

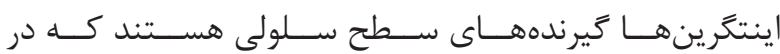

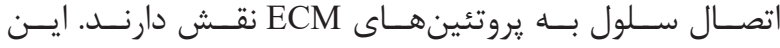

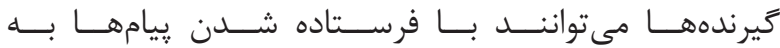

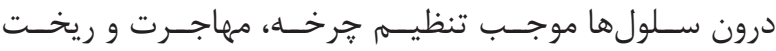

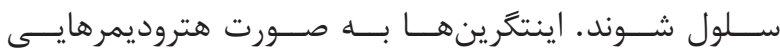

\footnotetext{
${ }^{22}$ Voltage-gated sodium channels

${ }^{23}$ Lineage

${ }^{24}$ Subventricular zone
}

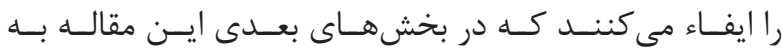

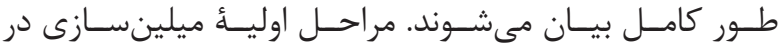
CNS

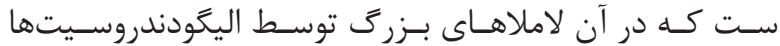

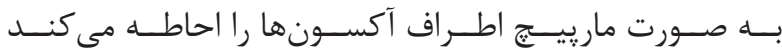

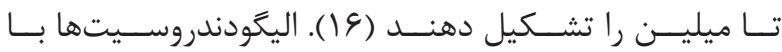

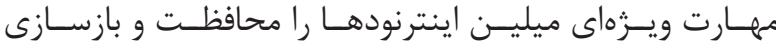

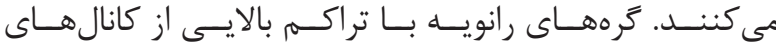

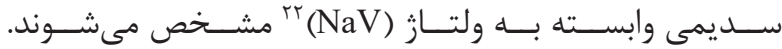

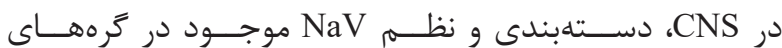

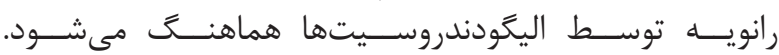

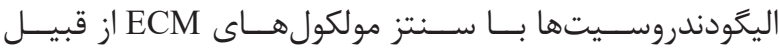

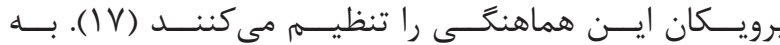

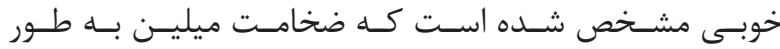

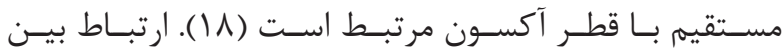

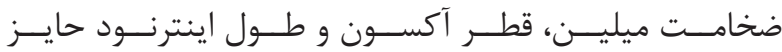

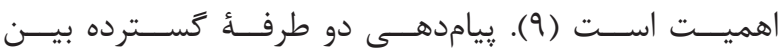

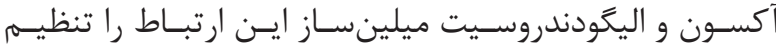

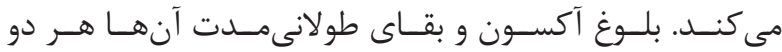

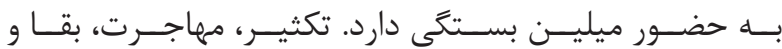

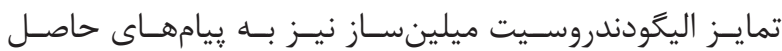

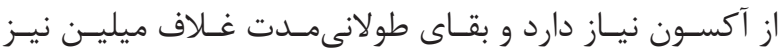

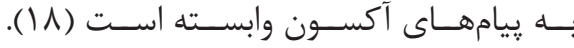

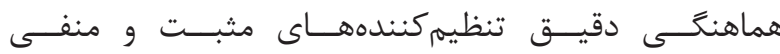

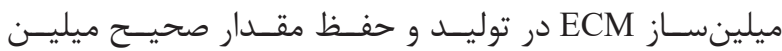

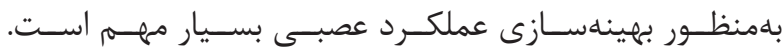

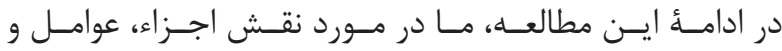

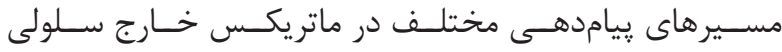

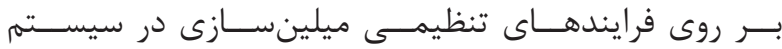

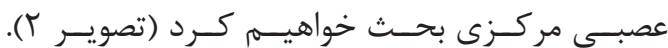

لامينين

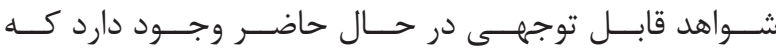

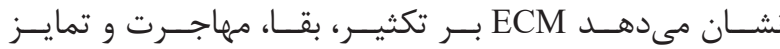

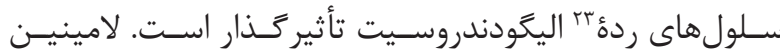

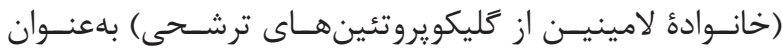

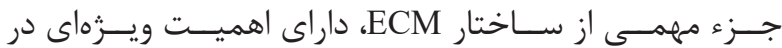

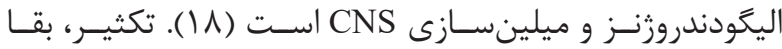

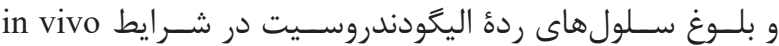

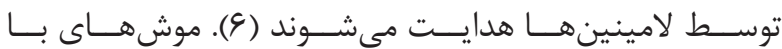

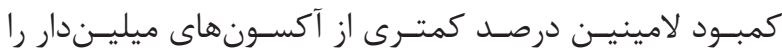

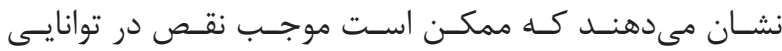

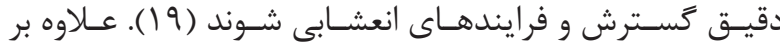

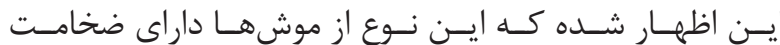

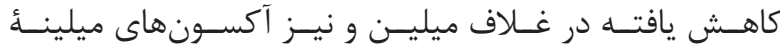

${ }^{25}$ Dystroglycan

${ }^{26}$ Filopodia

${ }^{27}$ Small interfering RNA 


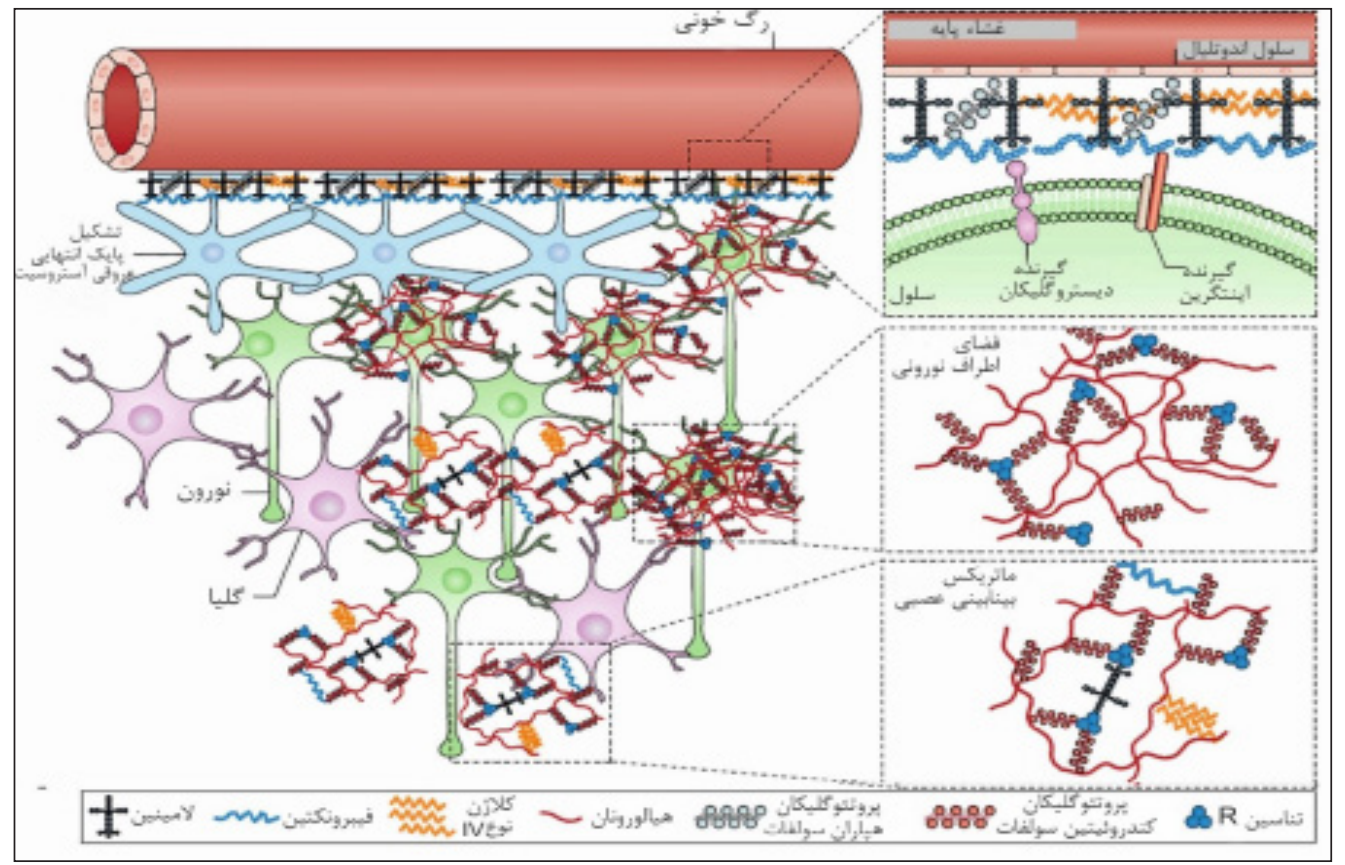

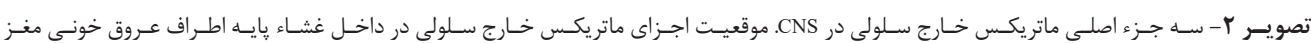

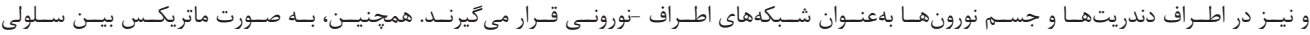

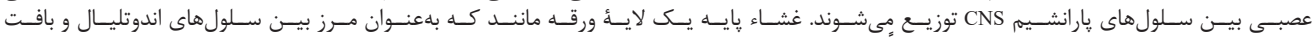

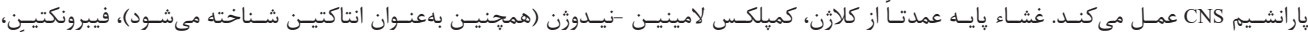

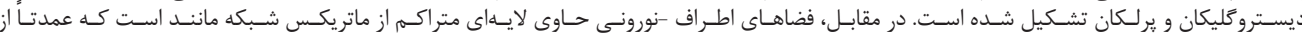

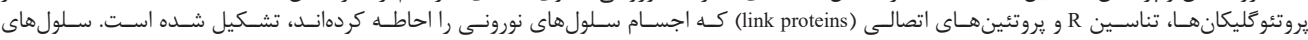

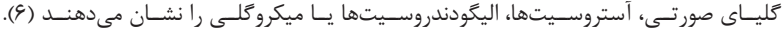

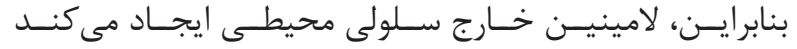

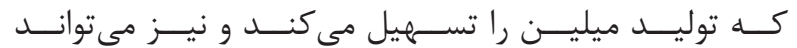

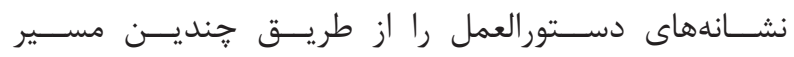

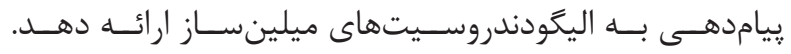

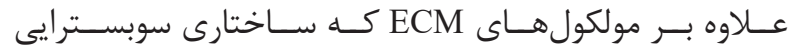

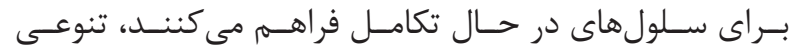

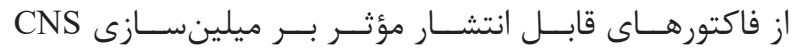

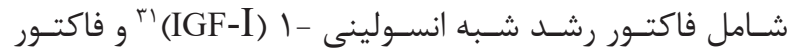

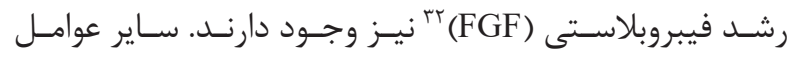

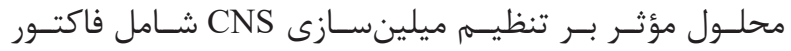

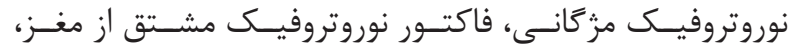

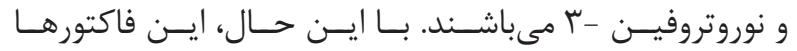

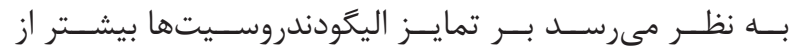

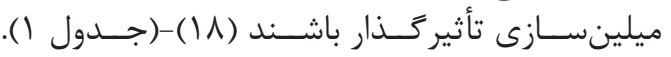
كلازن

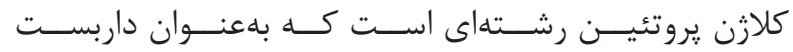

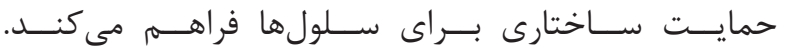

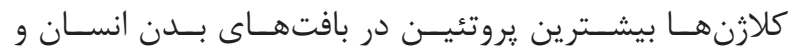

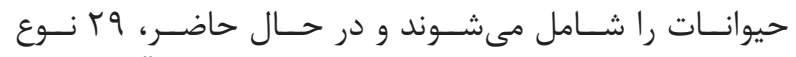

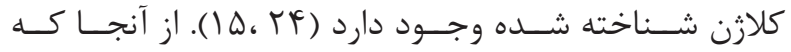

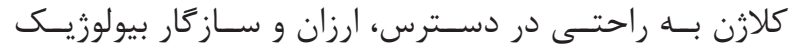

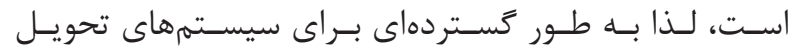

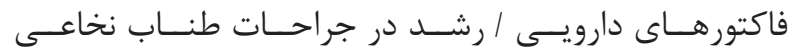

\footnotetext{
${ }^{28}$ Microdomain

${ }^{29}$ Integrin-linked kinase

${ }^{30}$ Myelinlike membrane
}

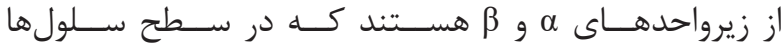

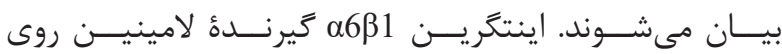

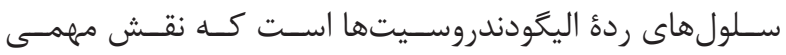

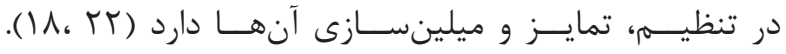

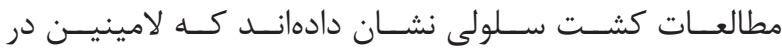

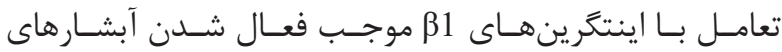

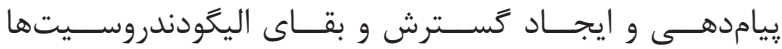

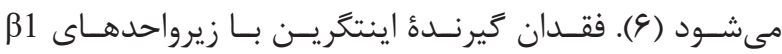

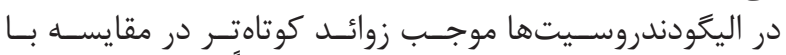

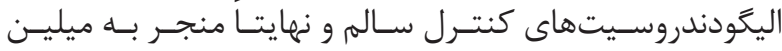

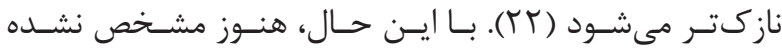

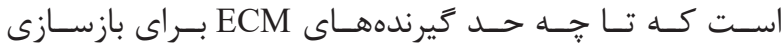

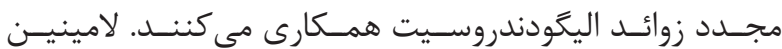

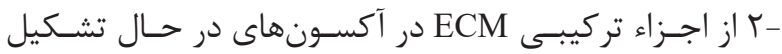
CNS

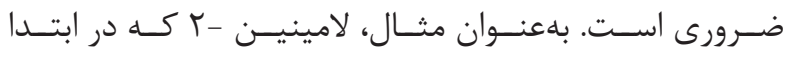

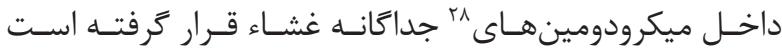

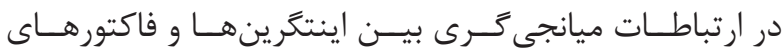

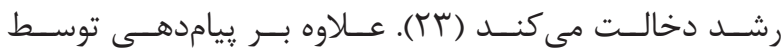

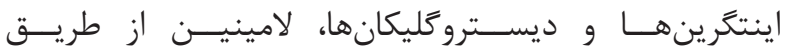

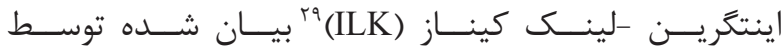

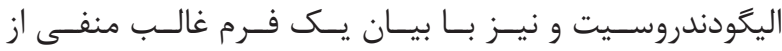

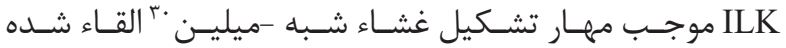

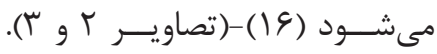

\footnotetext{
${ }^{31}$ Insulin-like growth factors

${ }^{32}$ Fibroblast growth factor
} 


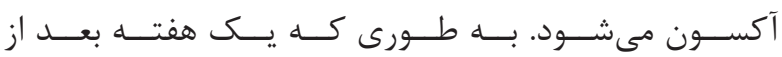

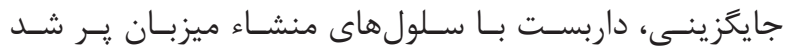

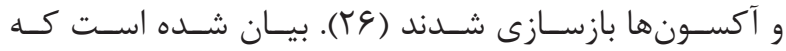

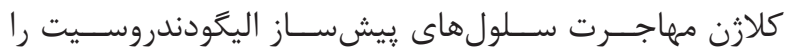

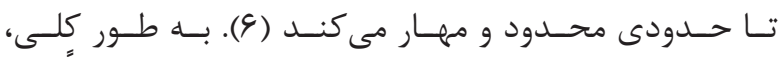

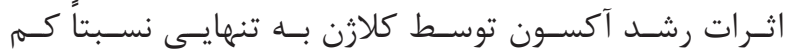

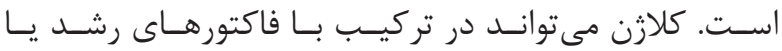

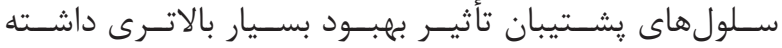

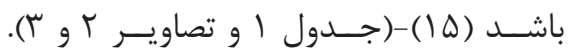

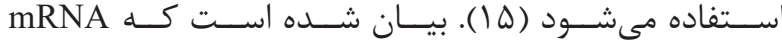

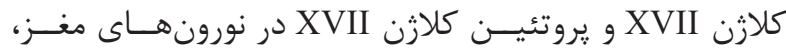

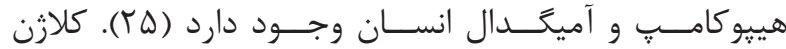

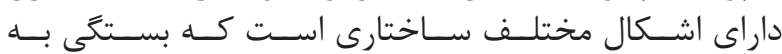

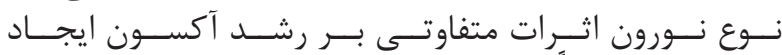

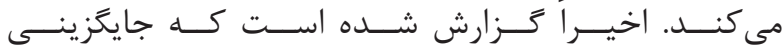

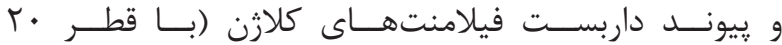

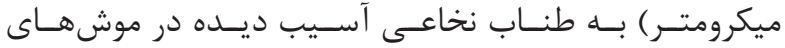

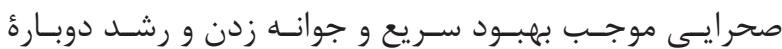

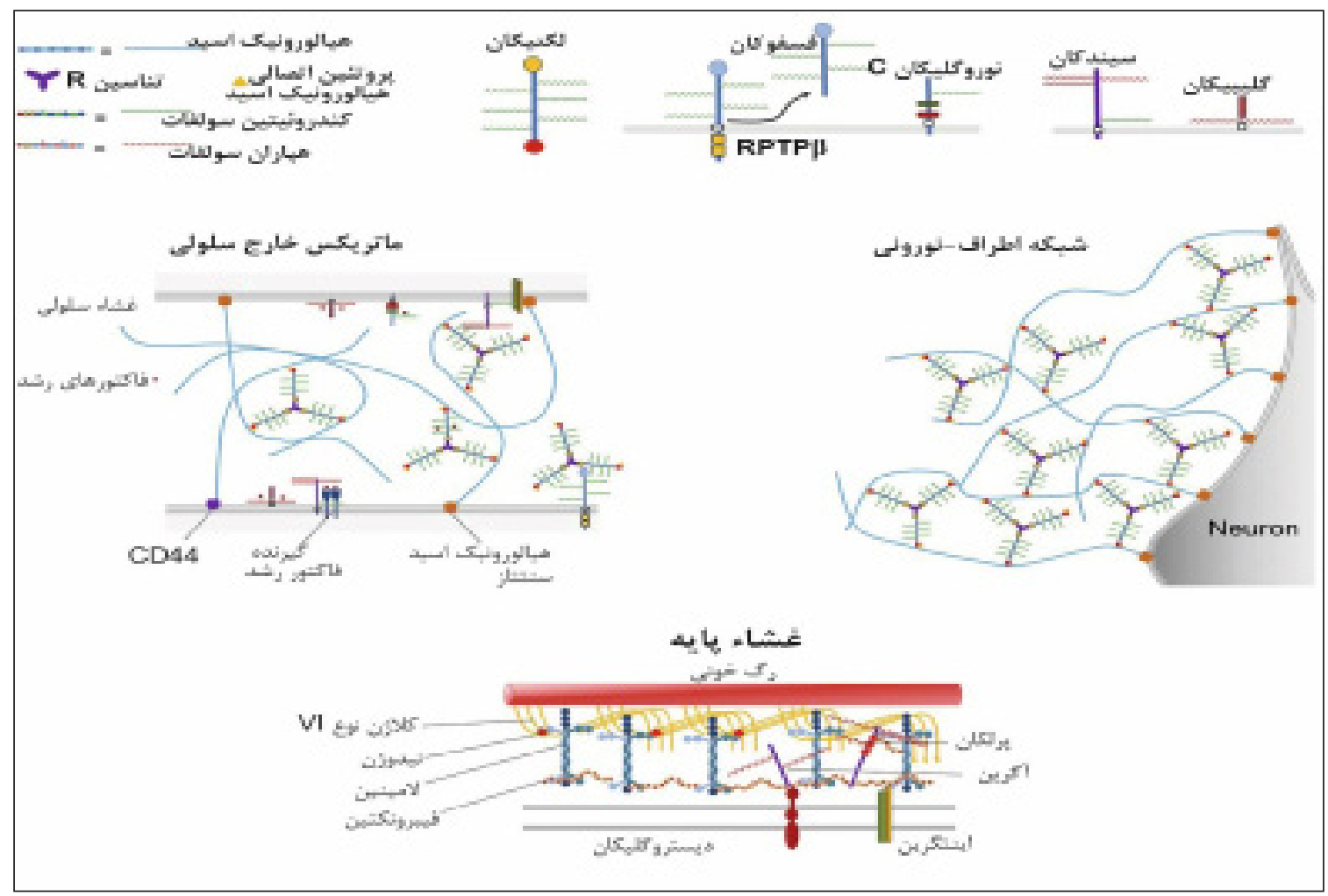

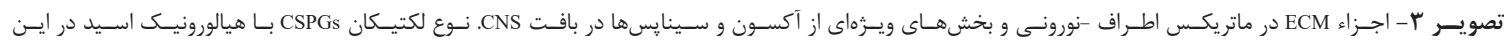

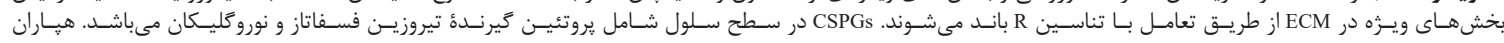

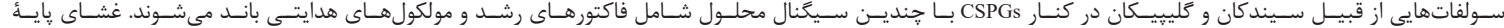

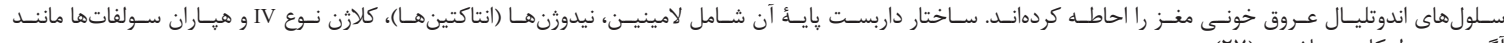

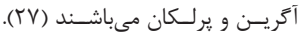

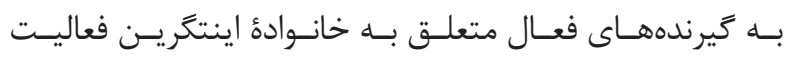

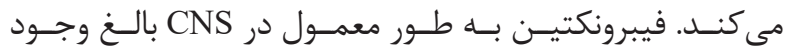

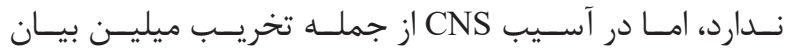

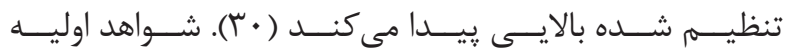

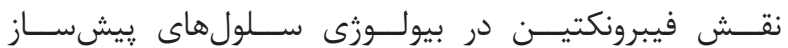

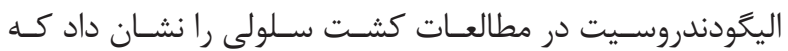

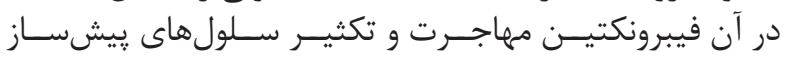

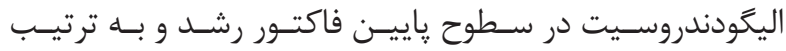

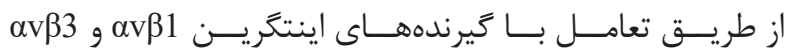

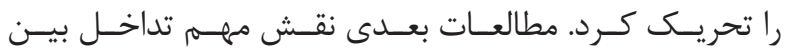

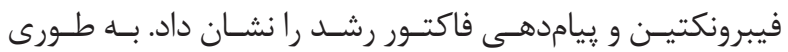

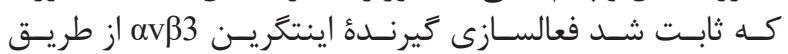

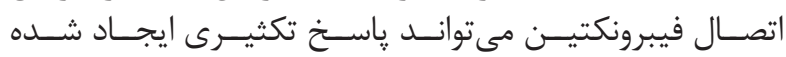

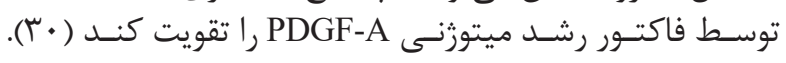

$$
\text { فيبرونكتين }
$$

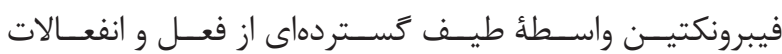

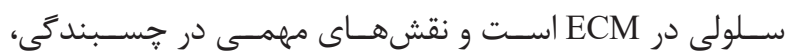

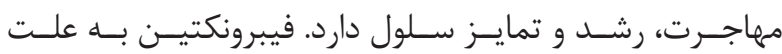

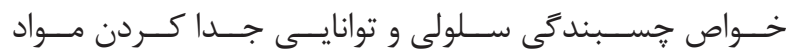

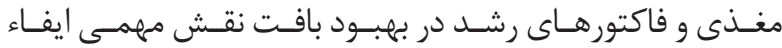

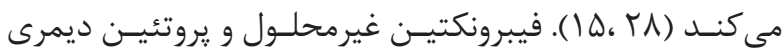

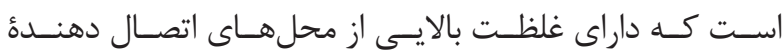

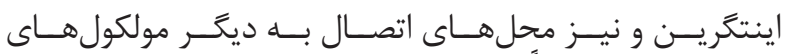
ECM

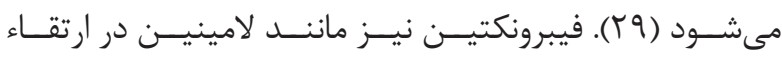

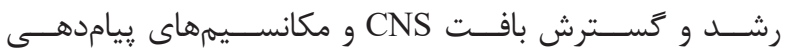

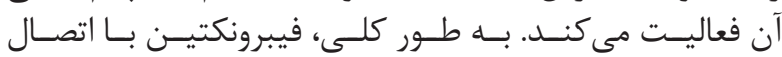




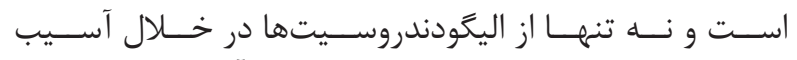

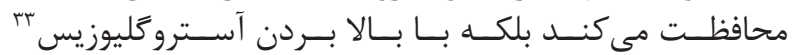

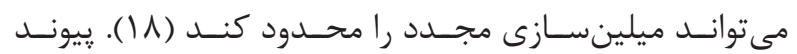

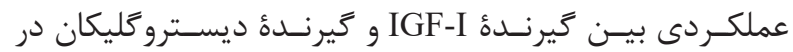

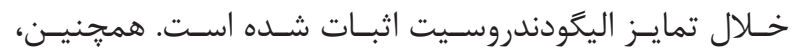

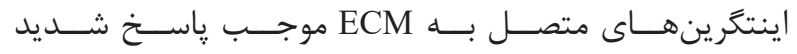

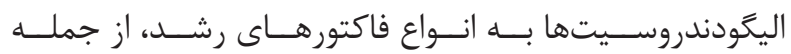

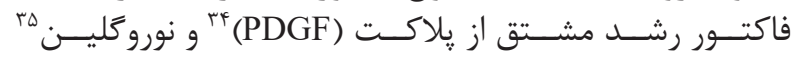

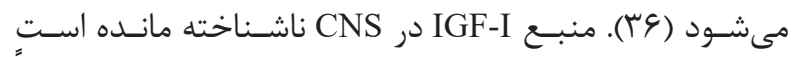

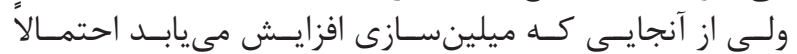

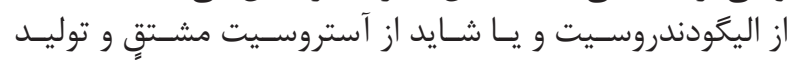

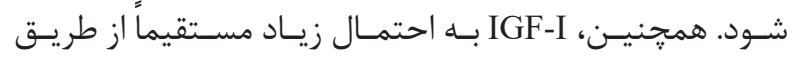

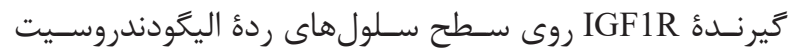

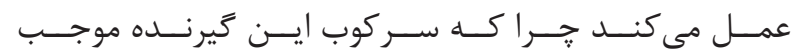

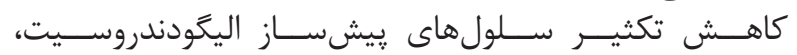

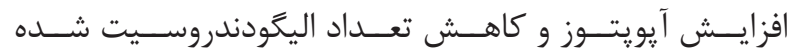

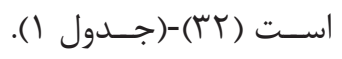

$$
\text { فاكتور رشد فيبروبلاستى }
$$

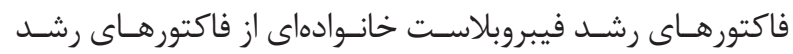

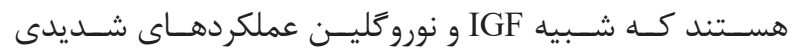

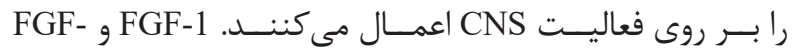

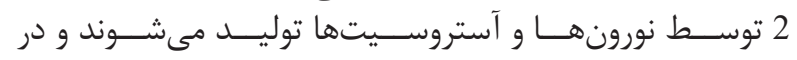

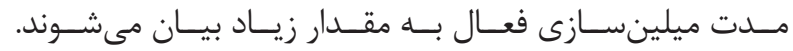
FGF

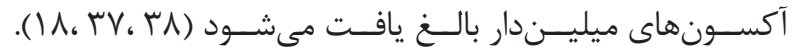

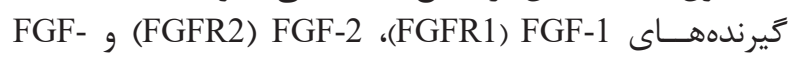

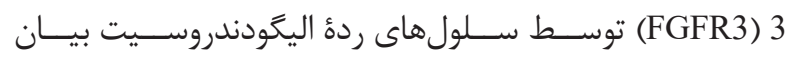

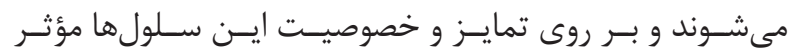

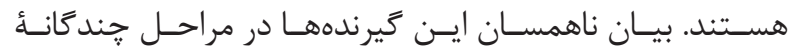

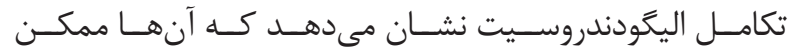

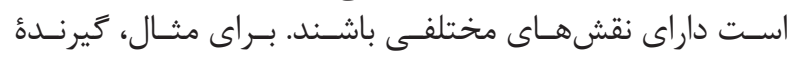

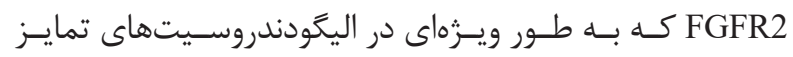

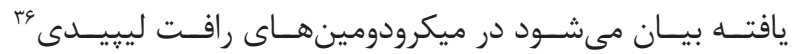

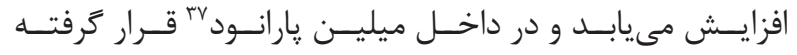

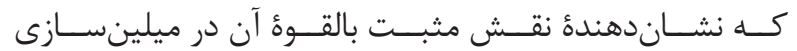

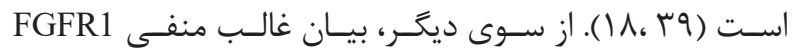

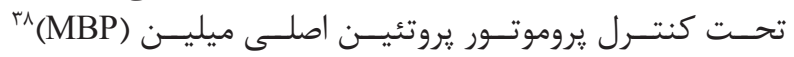

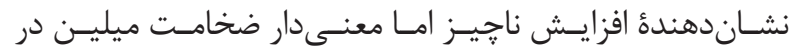

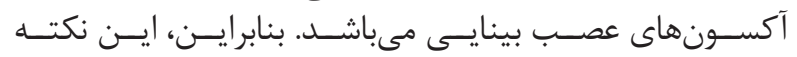

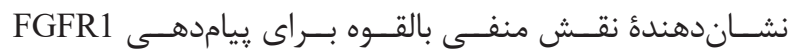

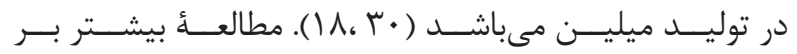

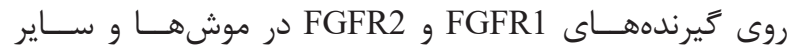

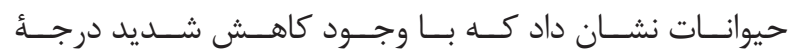

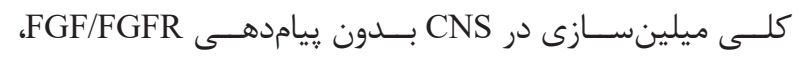

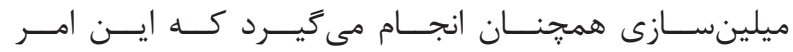

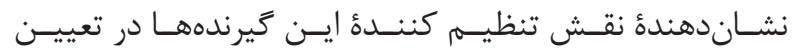

${ }^{33}$ Astrogliosis

${ }^{34}$ Platelet-derived growth factor

${ }^{35}$ Neuregulin
نتايـج ايـن مطالعـات حاكى از آن اسـت كه نقـش فيبرونكتين

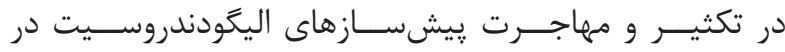

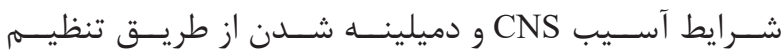

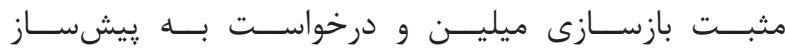

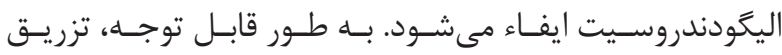

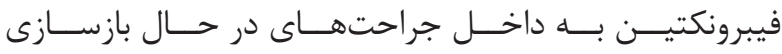

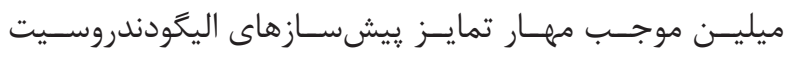

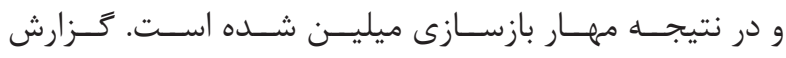

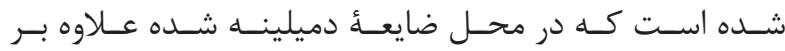

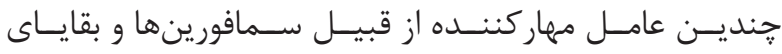

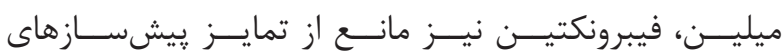

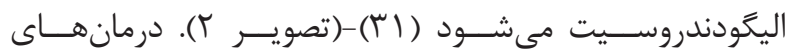

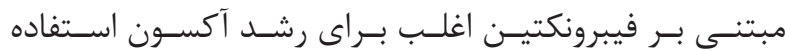

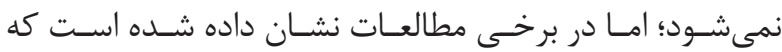

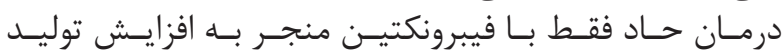

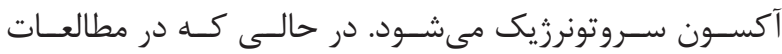

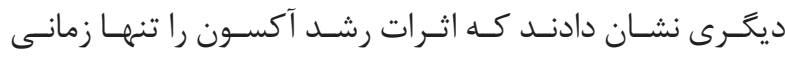

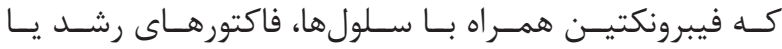

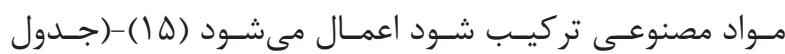

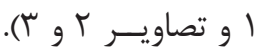
فاكتور رشد شبه انسولينى فاكتورهـــاى رشـــد شــبه انســـولين : يروتئينهايــى مشــابه

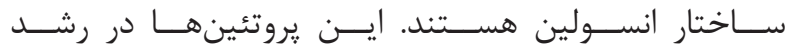

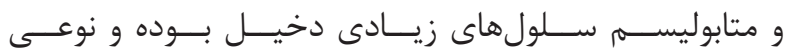

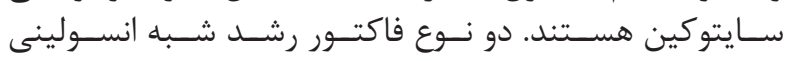

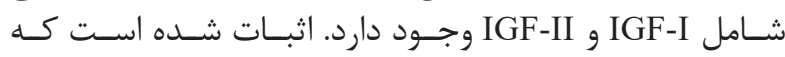

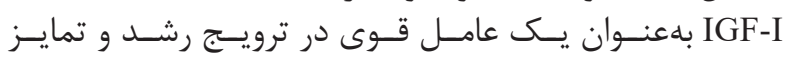

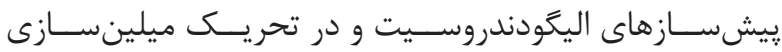

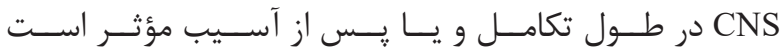

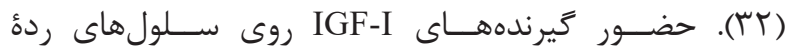

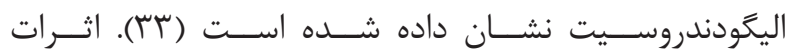
IGF-I

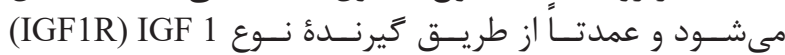

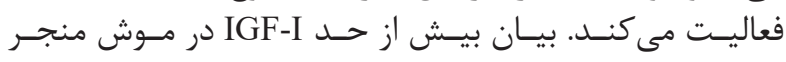

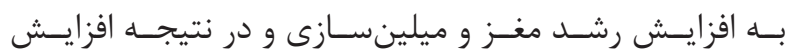

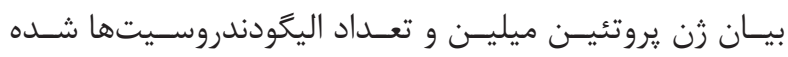

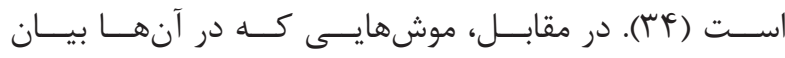

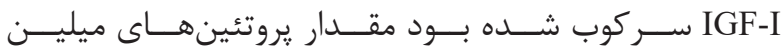

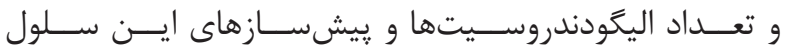

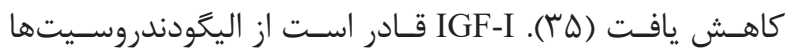

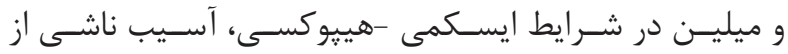

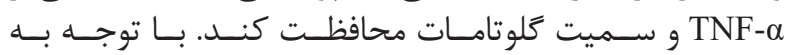

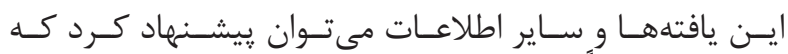

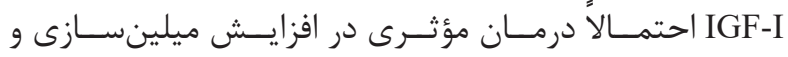

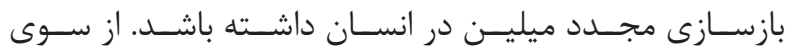

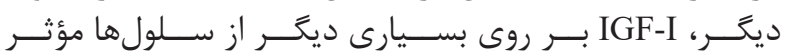

\footnotetext{
${ }^{36}$ Lipid-raft microdomains

${ }^{37}$ Paranodal

${ }^{38}$ Myelin basic protein
} 


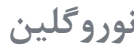

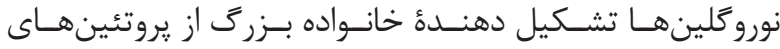

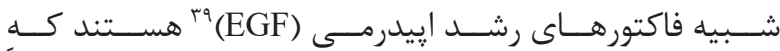

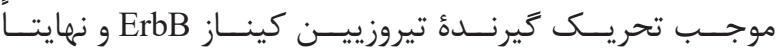

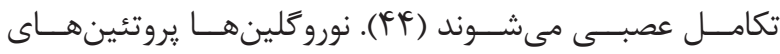

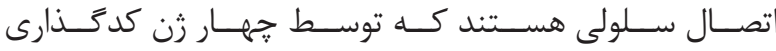

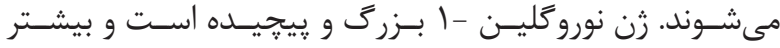

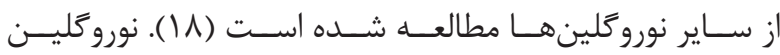

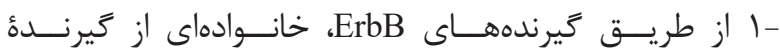

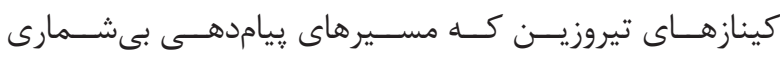

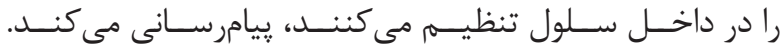

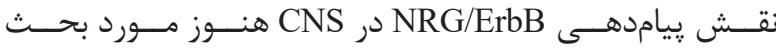

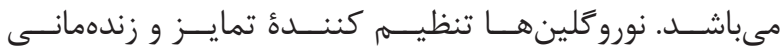

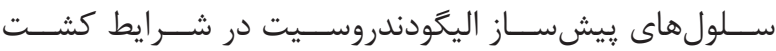

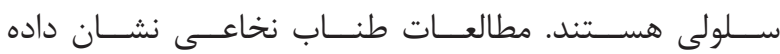

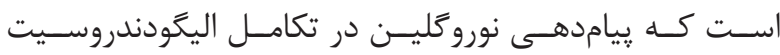

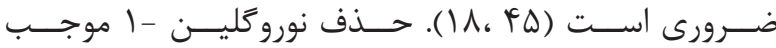

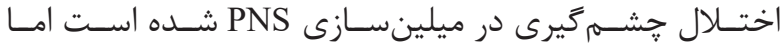

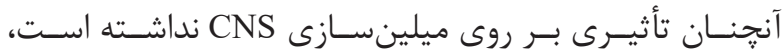

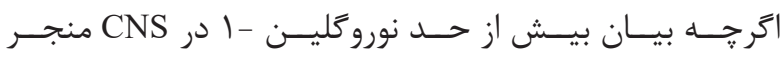

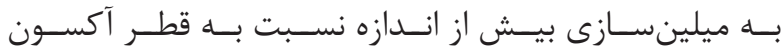

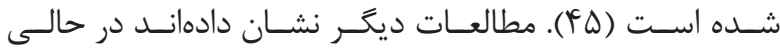

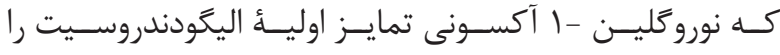

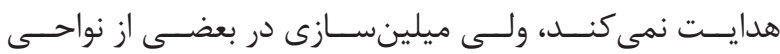

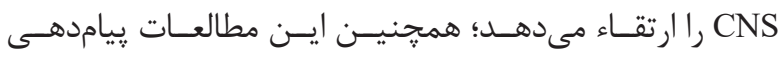
ErbB2

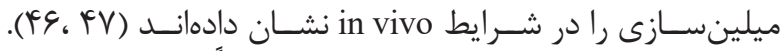

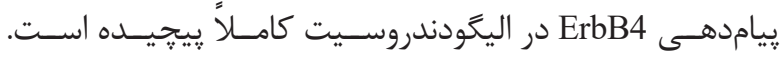

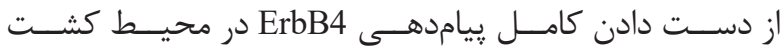

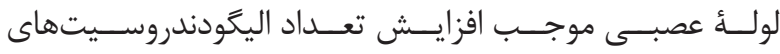

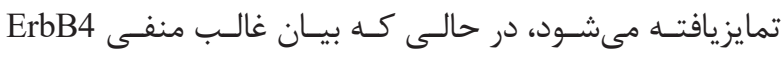

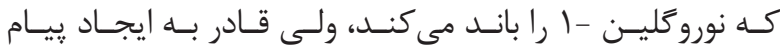

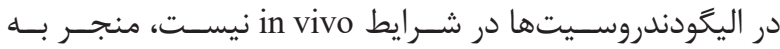

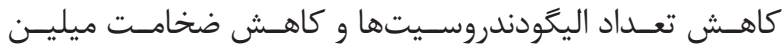

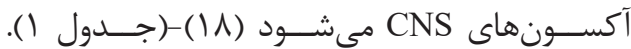

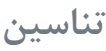

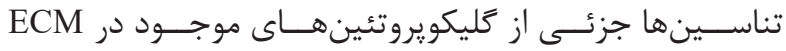

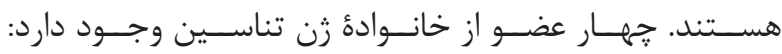

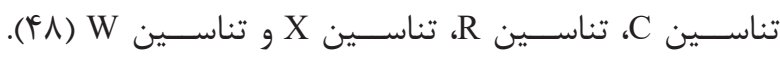

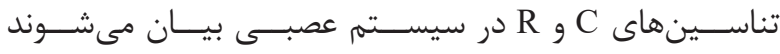

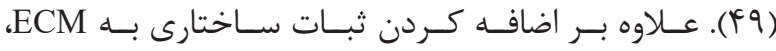

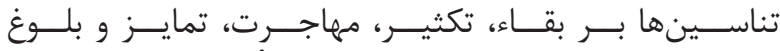

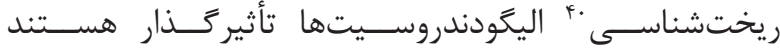

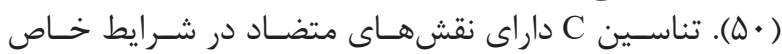

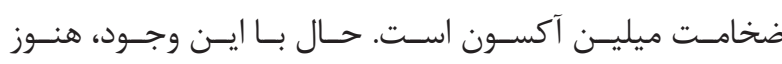

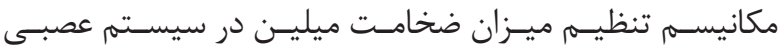

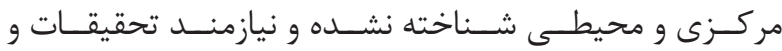

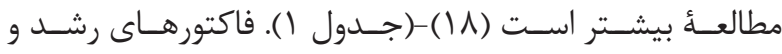

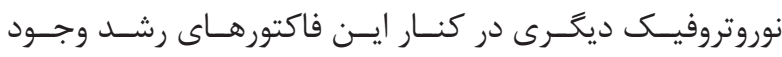

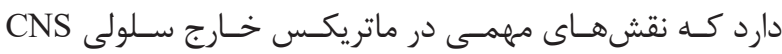

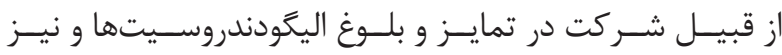

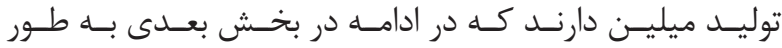

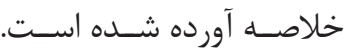

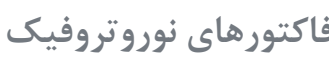

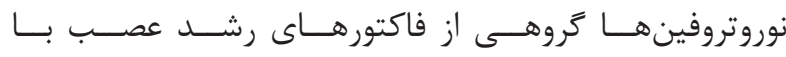

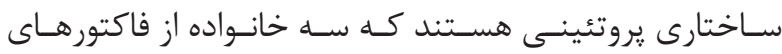

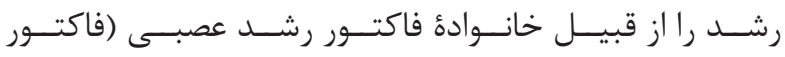

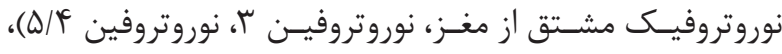

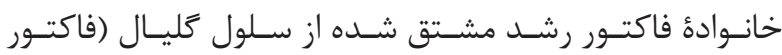

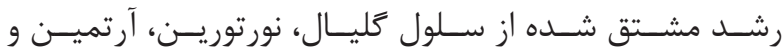

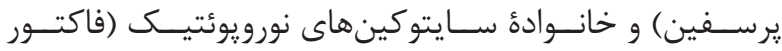

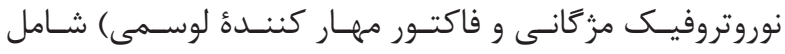

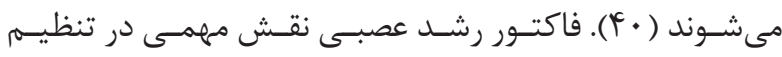

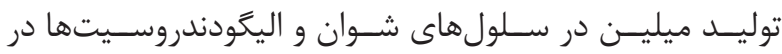

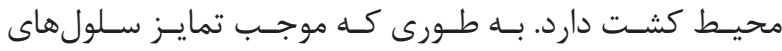

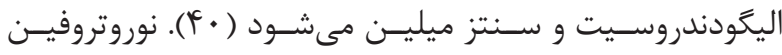

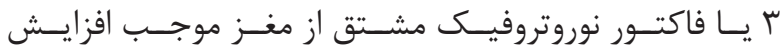

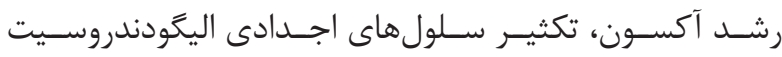

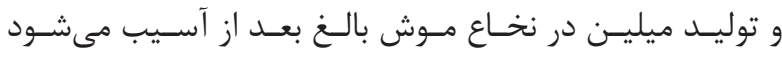

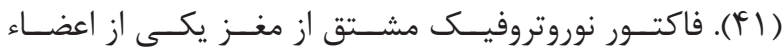

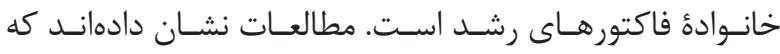

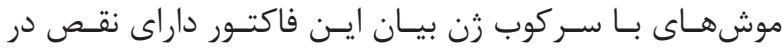

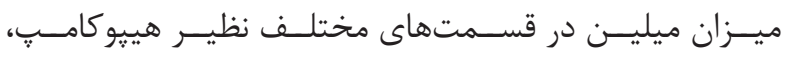

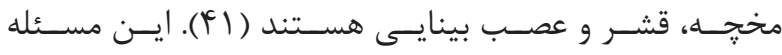

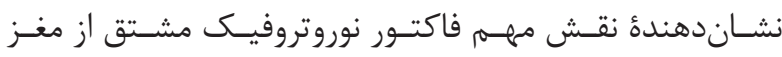

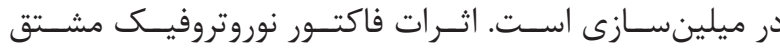

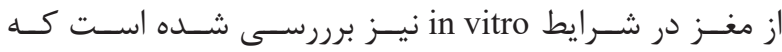

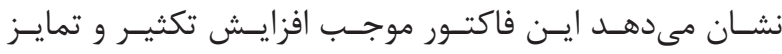

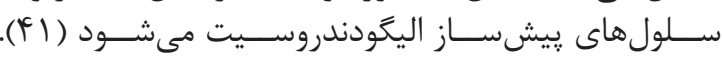

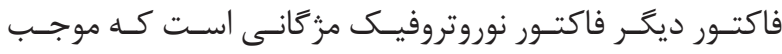

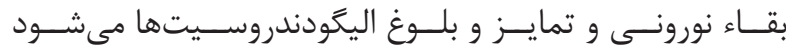

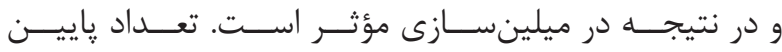

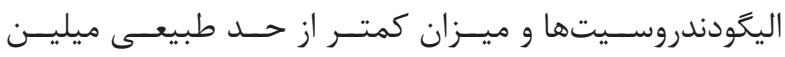

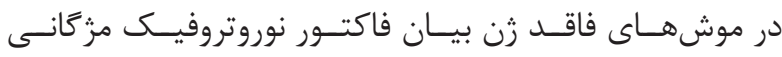

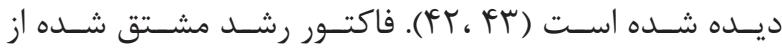

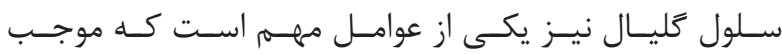

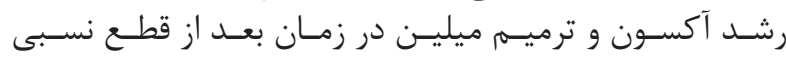

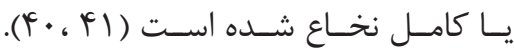

\footnotetext{
${ }^{39}$ Epidermal growth factor

${ }^{40}$ Morphology
} 


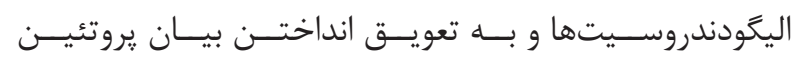

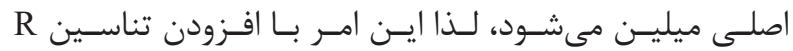

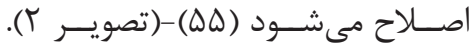
تر انسفرين

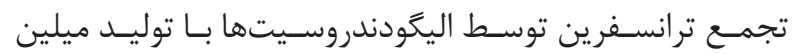

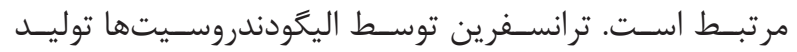

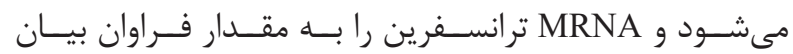

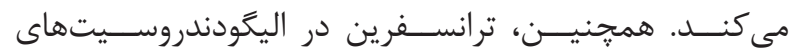

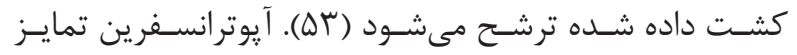

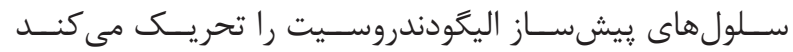

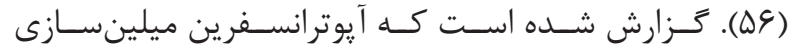

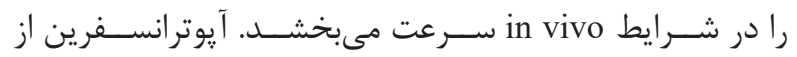

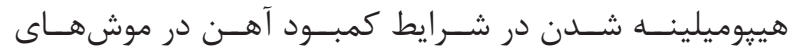

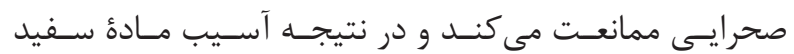

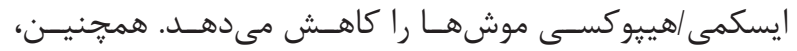

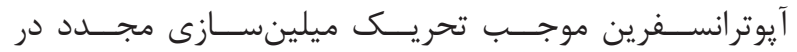

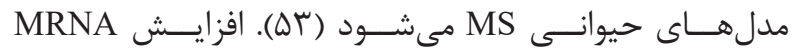

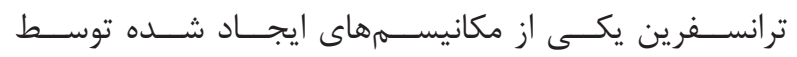

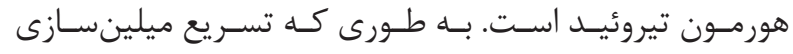

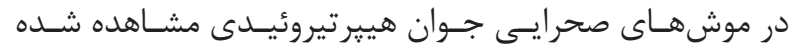

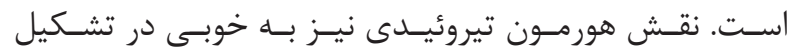

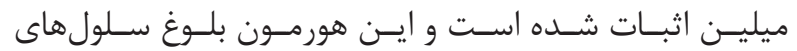

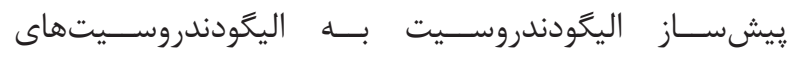

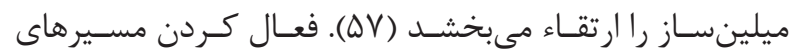

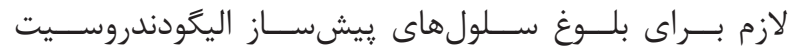

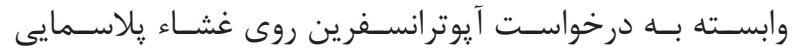

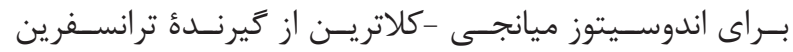

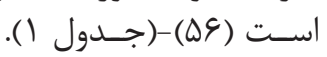

سمافورين

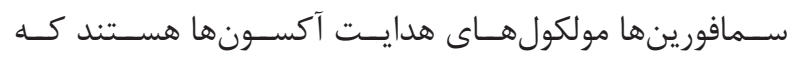

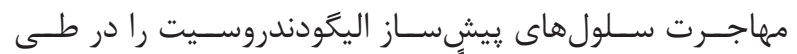

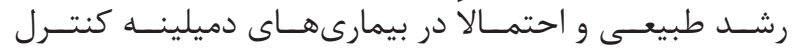

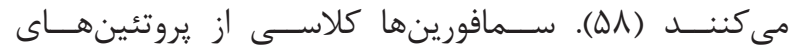

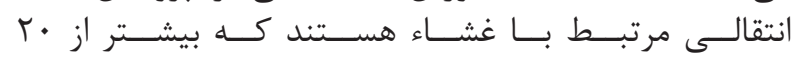

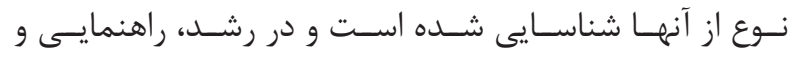

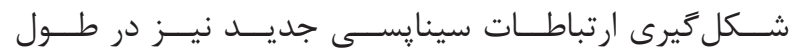

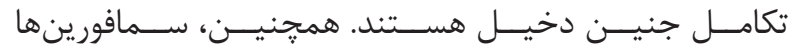

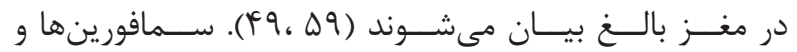

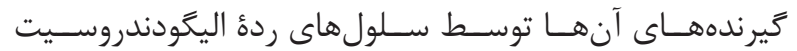

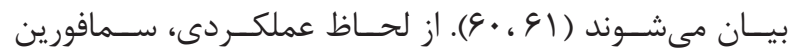

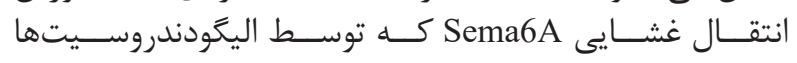

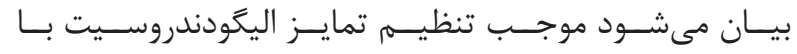

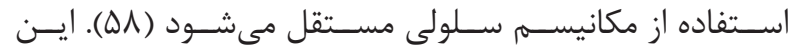

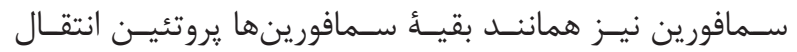

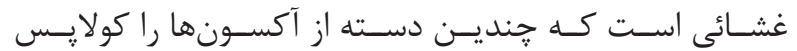

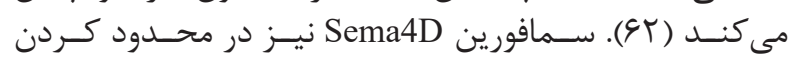

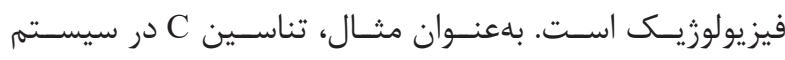

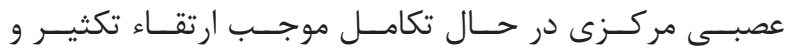

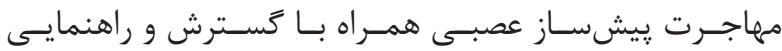

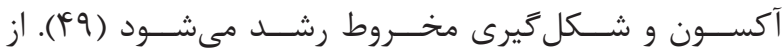

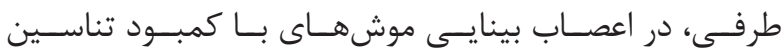

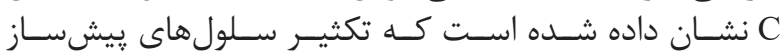

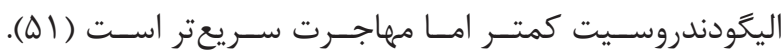

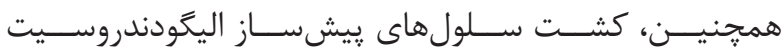

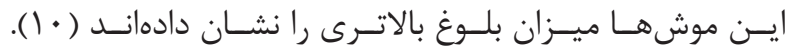

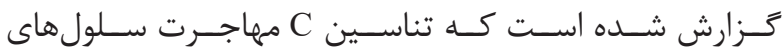

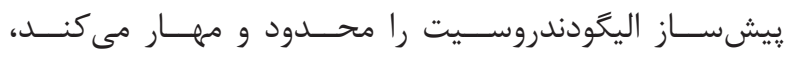

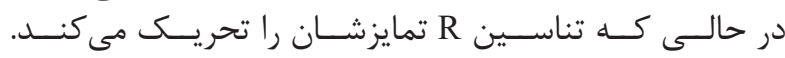

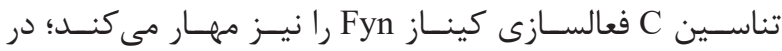

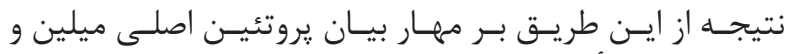

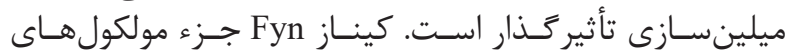

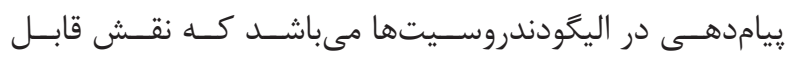

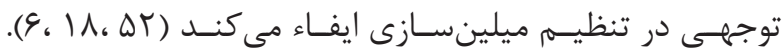

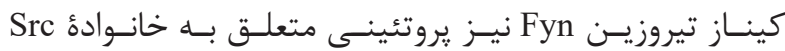

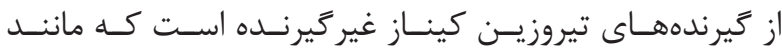
Src و Syn

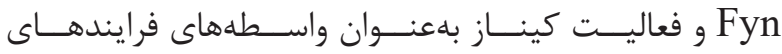

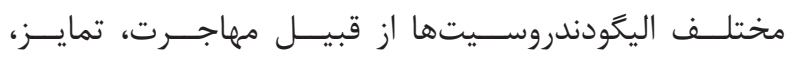

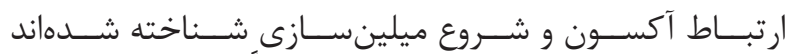

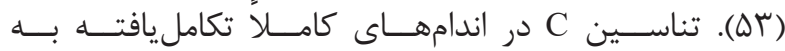

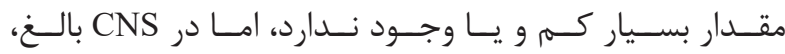

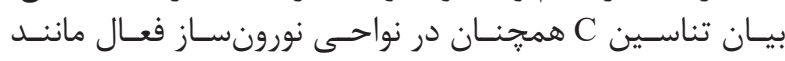

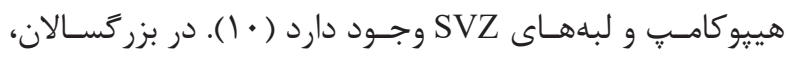

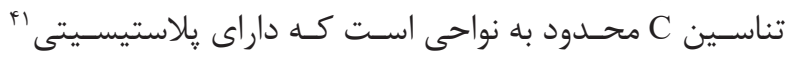

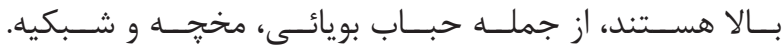

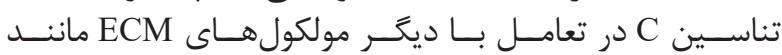

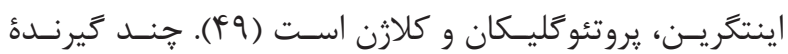

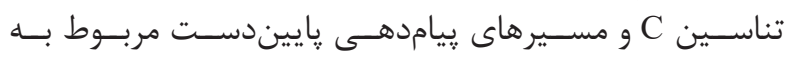

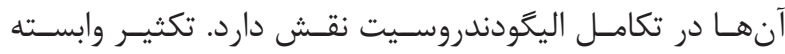

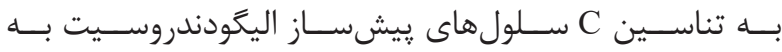

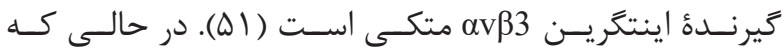

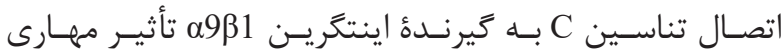

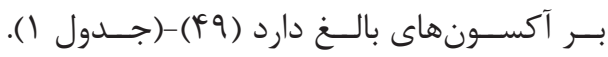

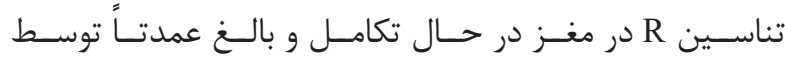

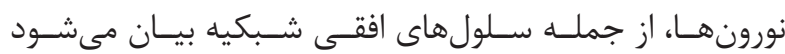

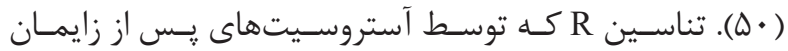

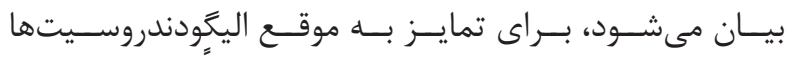

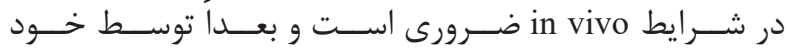

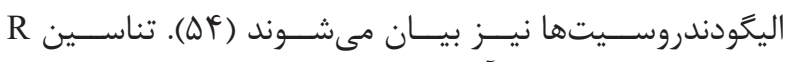

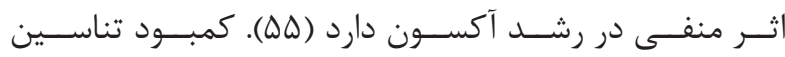

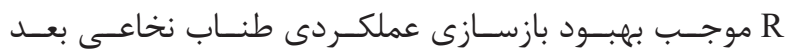

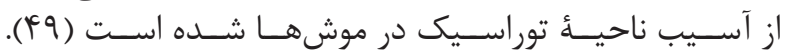

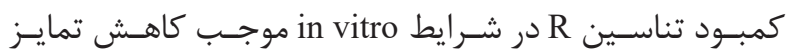

${ }^{41}$ Plasticity 
اليخودندروسـيتها هسـتند. در حضـور لايــاى از CSPGs در كار

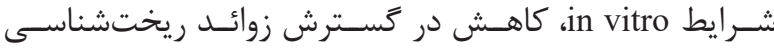

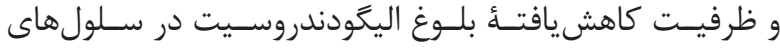

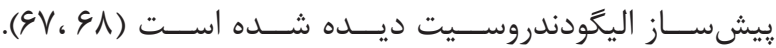

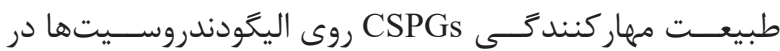

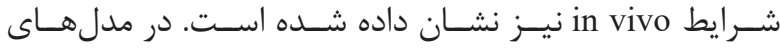

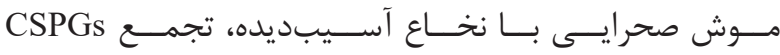

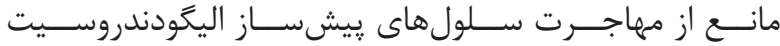

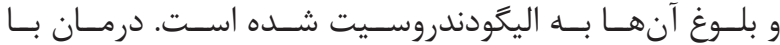

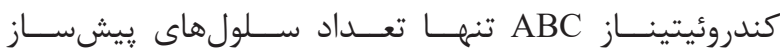

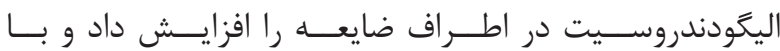

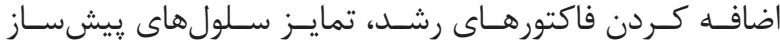

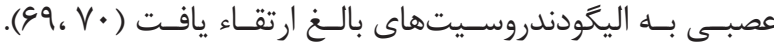

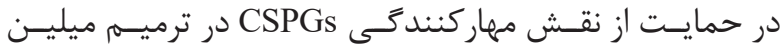

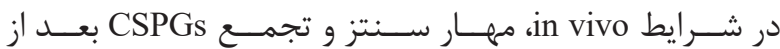

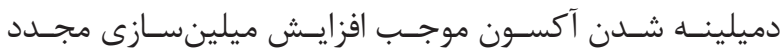

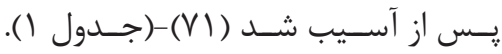

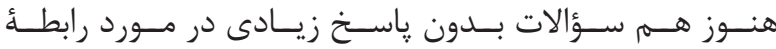

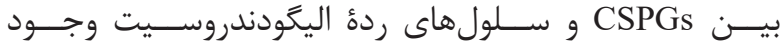

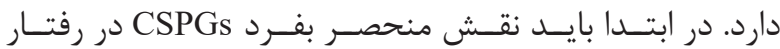

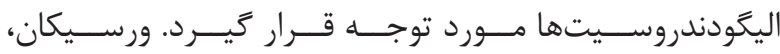

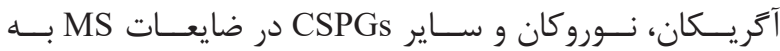

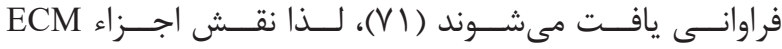

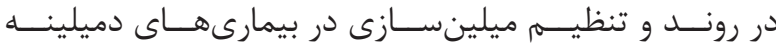

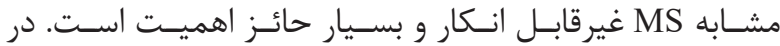

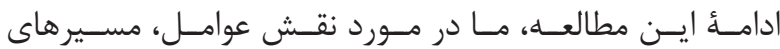

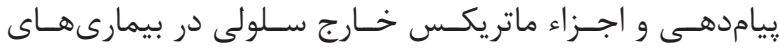

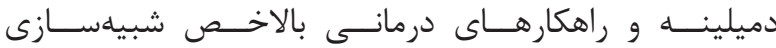

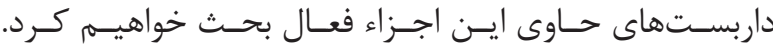

نقش ECM در بيمارى هاى دميلينه

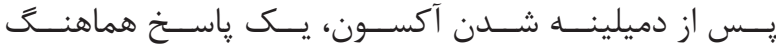

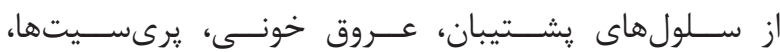

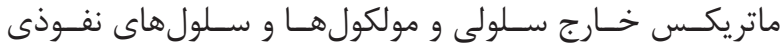

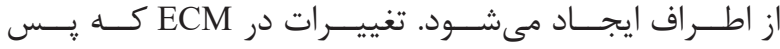

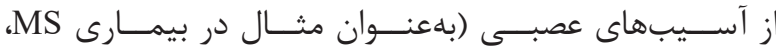

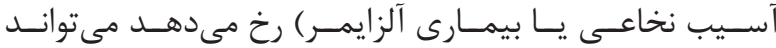

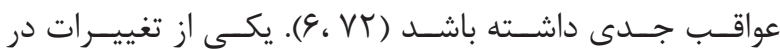

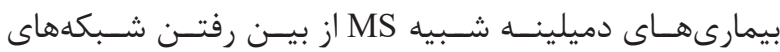

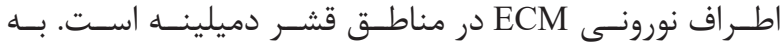

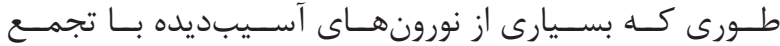

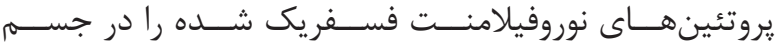

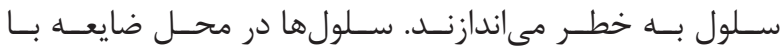

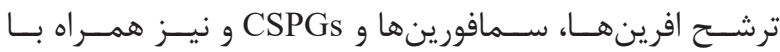

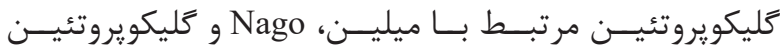

${ }^{42}$ Chondroitin sulphate proteoglycans

${ }^{43}$ Aggrecan

${ }^{44}$ Neurocan
بازســازى ميليــن از طريـق تعـدادى از مكانيسـهمها از جملـهـ

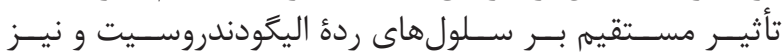

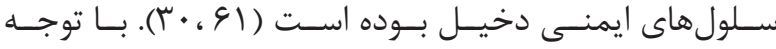

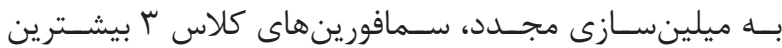

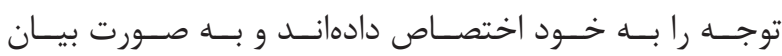

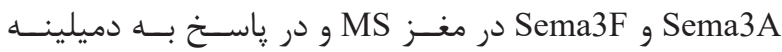

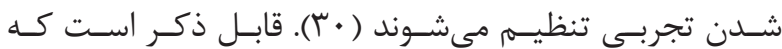

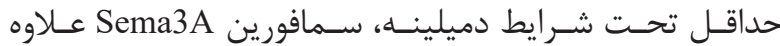

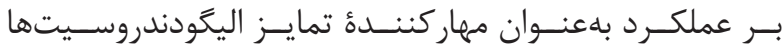

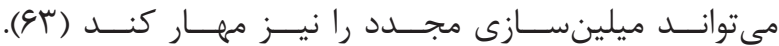

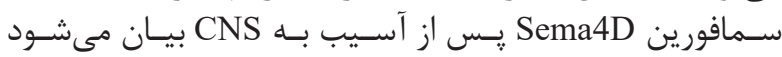

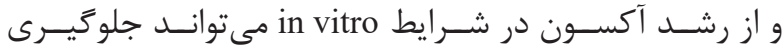

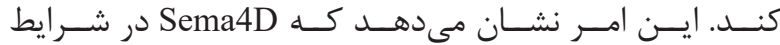
in vivo

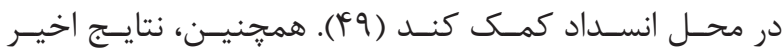

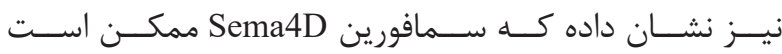

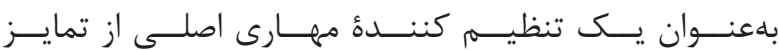

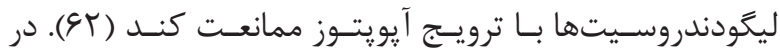

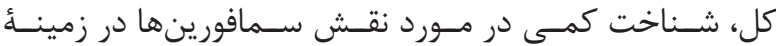

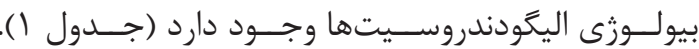
كندروئيتين سولفات

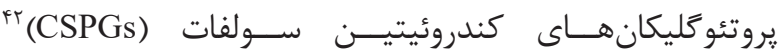

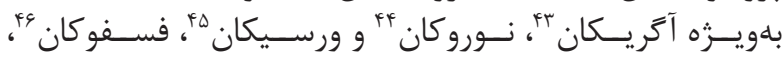

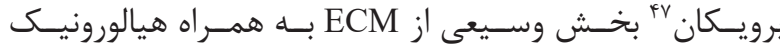

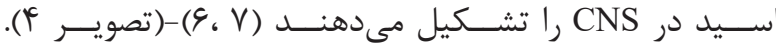

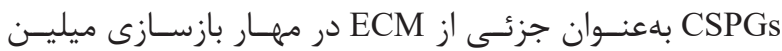

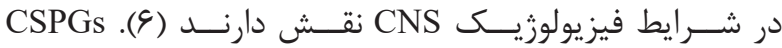

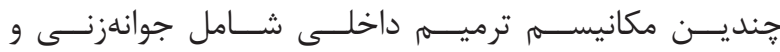

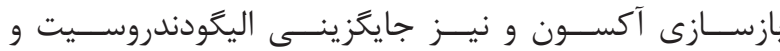

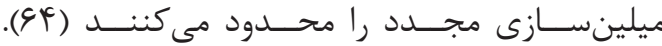

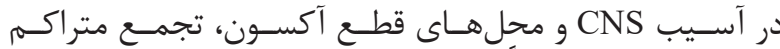

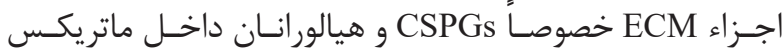

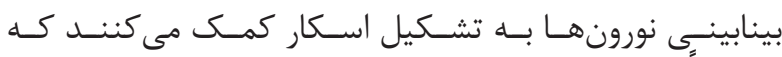

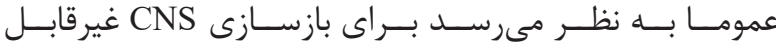

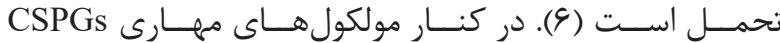

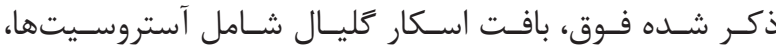

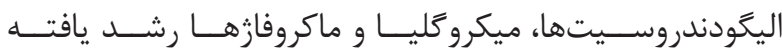

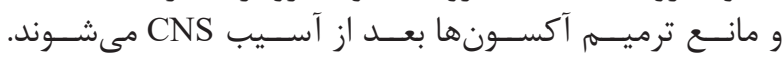

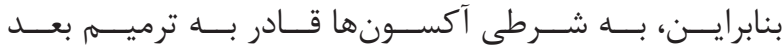

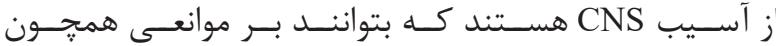

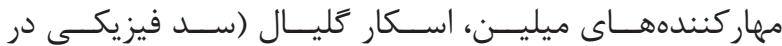

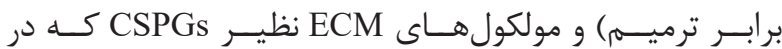

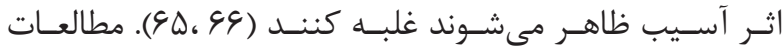

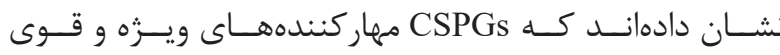

${ }^{45}$ Versican

${ }^{46}$ Phosphacan

${ }^{47}$ Brevican 


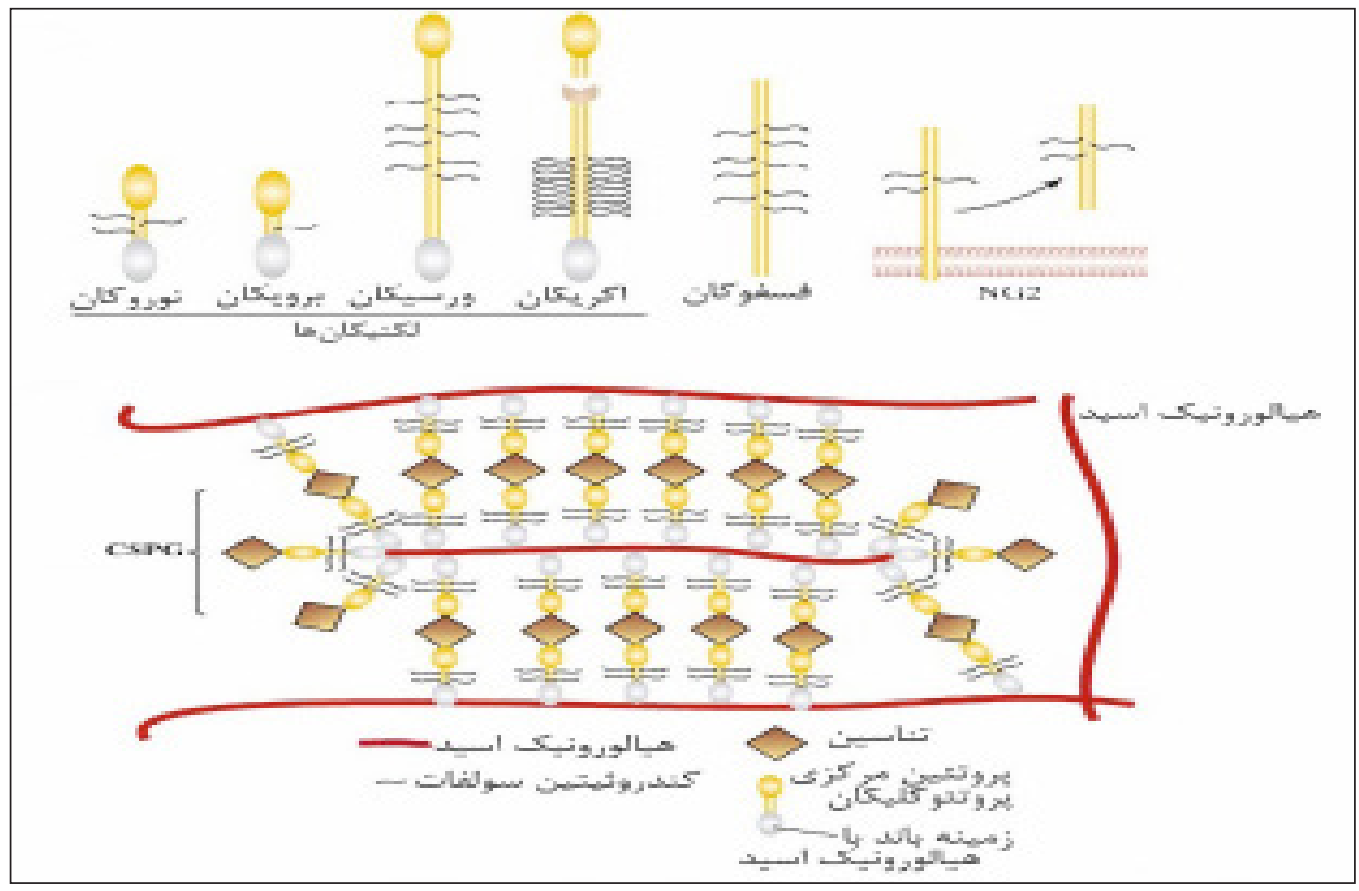

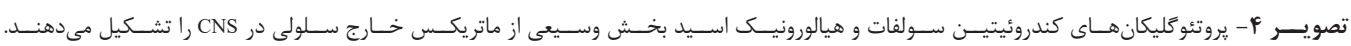

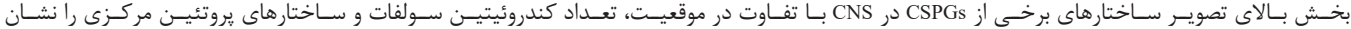

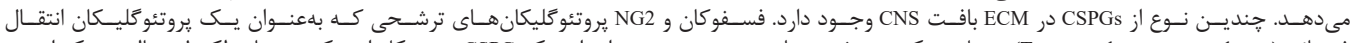

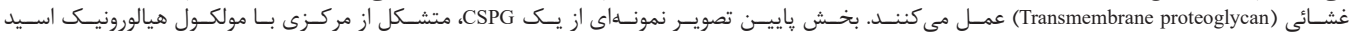

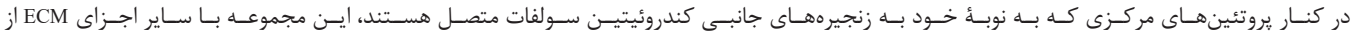

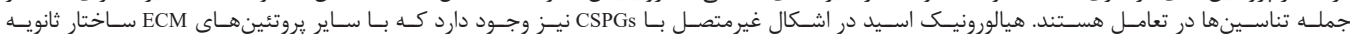

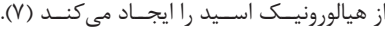

جدول ا- عملكرد انواع مولكولهاى مهم ECM در سيستم اعصاب مركزى.

\begin{tabular}{|c|c|c|}
\hline منيع & توفيح & مولكولهاي ECM E \\
\hline$(1 / 19)$ & 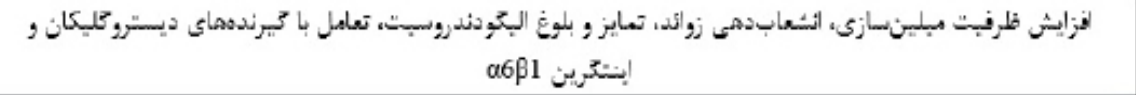 & لامينين \\
\hline$(\varphi \cdot T \cdot)$ & 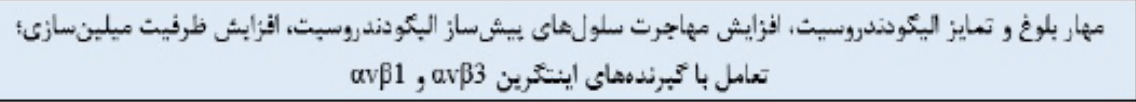 & فيبرونكتين \\
\hline (f) & مهار ههاجرث سلول ماي بيشساز البيُوندروسيث & كلازقن \\
\hline (Tr. TF. TF) & 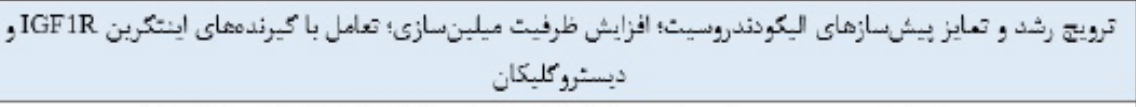 & IGF-I \\
\hline (1A. זQ) & 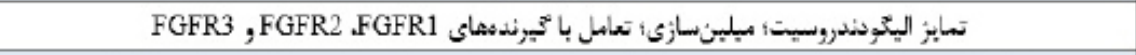 & FGF \\
\hline$(1 \lambda, \uparrow \Delta)$ & افزايش تعداد البكودندروسبتثاى تعابزيافثه؛ مؤثر بر ضخاهت مبلين؛ تعامل با كيرنسهاى ErbB & نورؤكلين \\
\hline$\left(1 \Lambda_{x} \Delta r\right)$ & تعايز و بلوغ البكودندروسيت؛ تحريكى بيان بروتثبن مبلين، تعامل با كيرندههاى كيناز تيروزبن Fyn و ينتكرين & ت تناسين R \\
\hline$(\% 9, \Delta 1, \Delta r)$ & 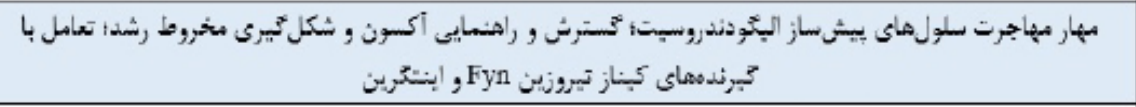 & تناسين C \\
\hline$(\Delta G, \Delta V)$ & تمايز سلولهاى بيشساز اليكودندروسيت: تحريك ميليئسازى مجددد & تراتسفرين \\
\hline$(\% 9,95)$ & ههار ميلينسازى هجدد؛ تنظيهم و ههار تمايز اليكودندروسبت & سمافورين \\
\hline$\left(9,9+9 V^{\prime}\right)$ & مهار ميلينسازى هجدد؛ مهار تمايز و بلوغ البكودندروسبت، & كندروئيتين سولفات \\
\hline
\end{tabular}

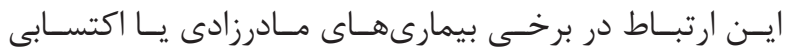

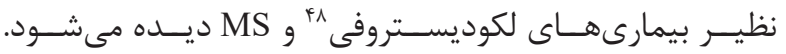

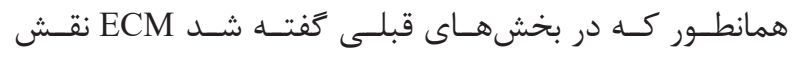

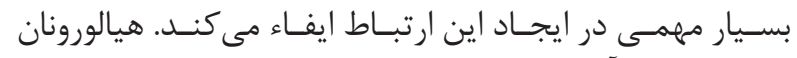

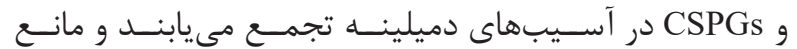

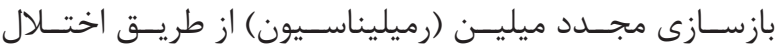
${ }^{48}$ Leukodystrophies
اليخودندروسـيت ميليـن كـه اكثـراً توسـط اليخودندروسـيتها

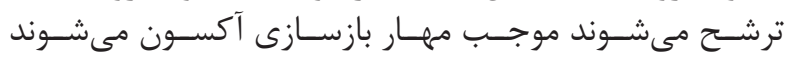

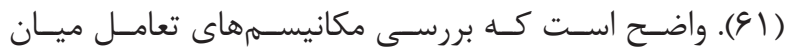

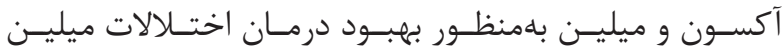

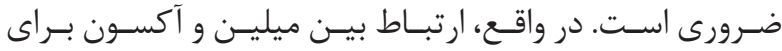

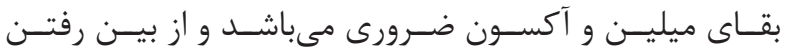




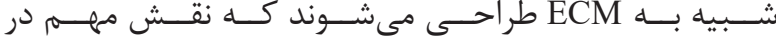

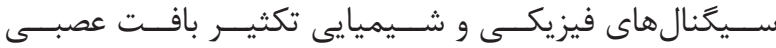

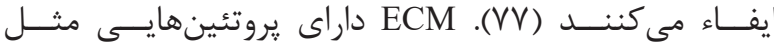

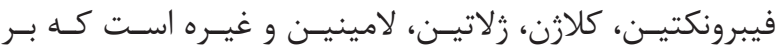

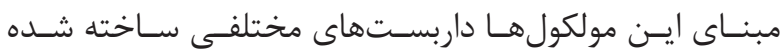

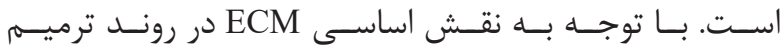

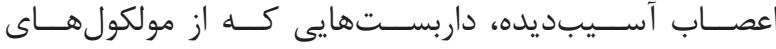

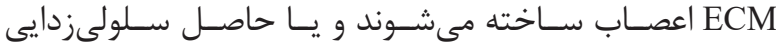

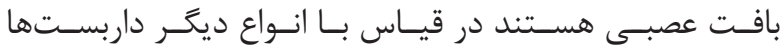

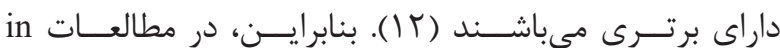

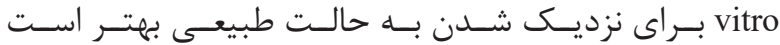

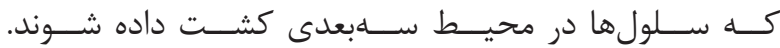

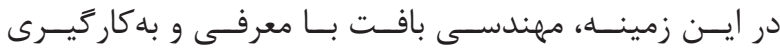

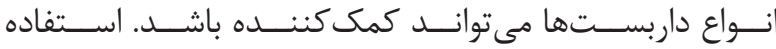

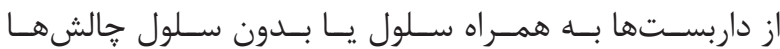

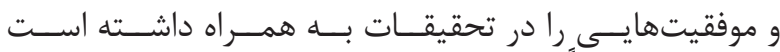

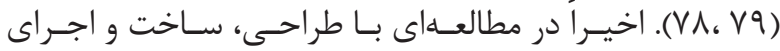

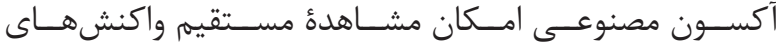

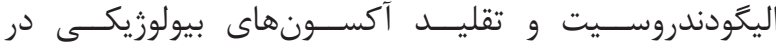

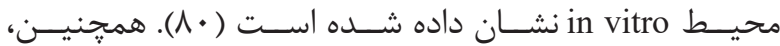

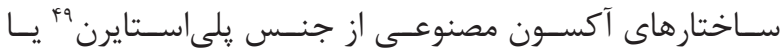

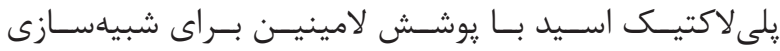

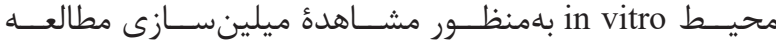

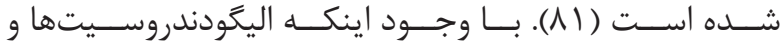

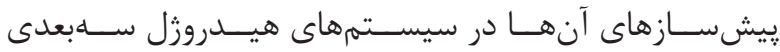

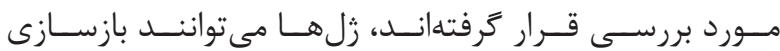

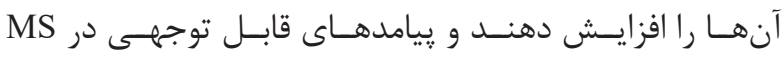

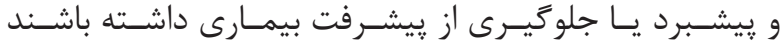

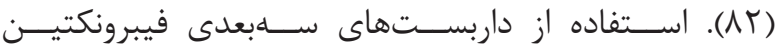

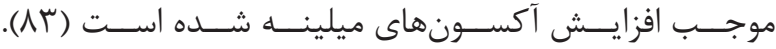

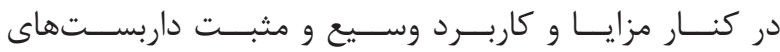

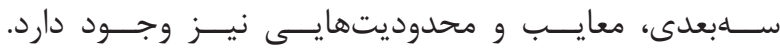

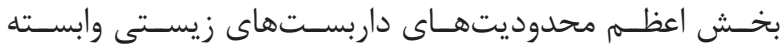

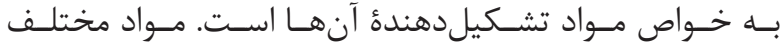

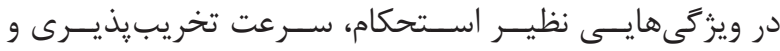

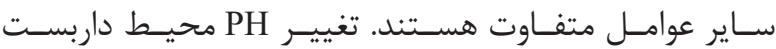

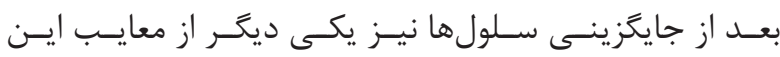

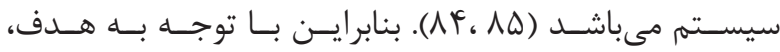

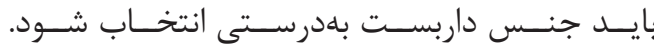

\section{نتيجه گيرى}

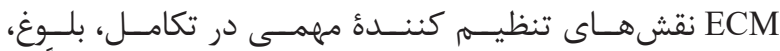

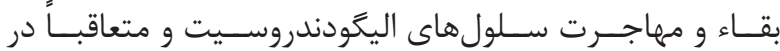

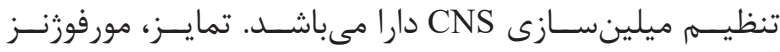

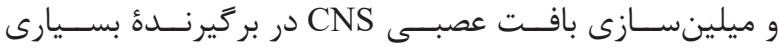

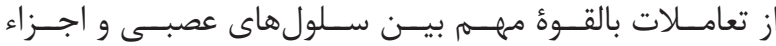

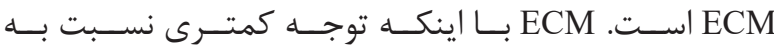

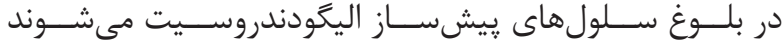

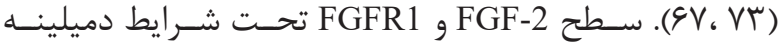

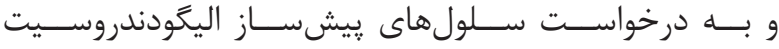

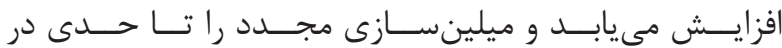

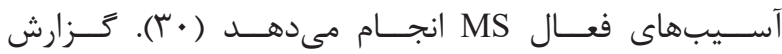

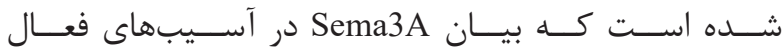

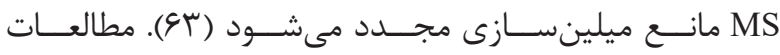

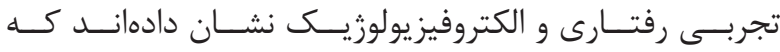

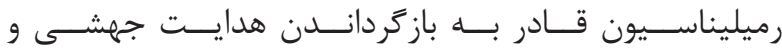

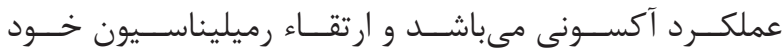

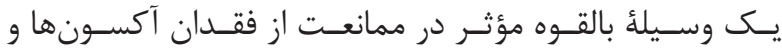

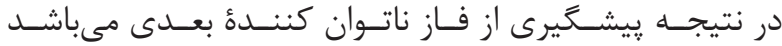

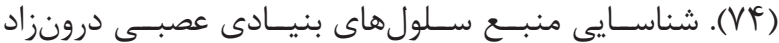

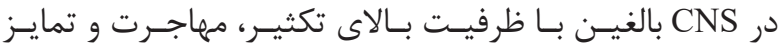

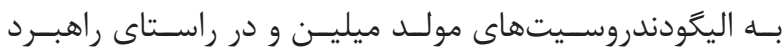

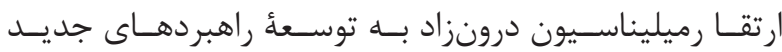

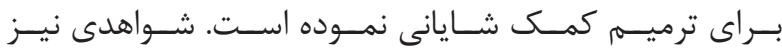

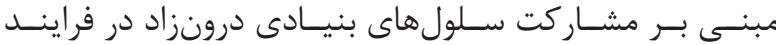

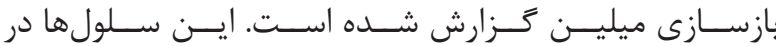

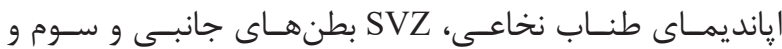

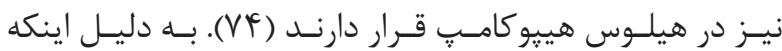

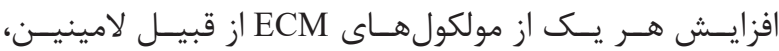

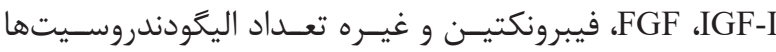

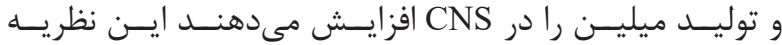

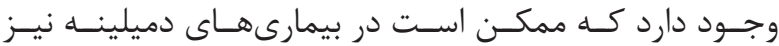

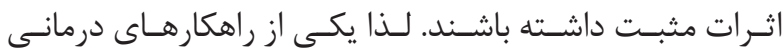

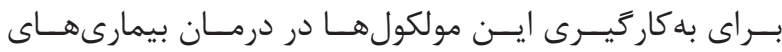

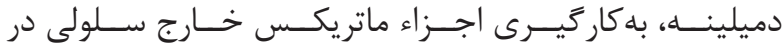

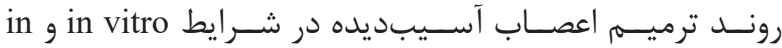
مى vivo محيطهاى سهبعدى و اثر بر ميلينسازى

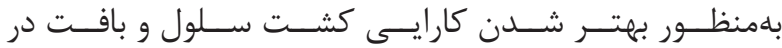

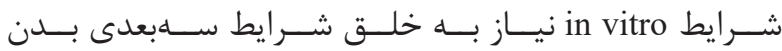
(in vivo)

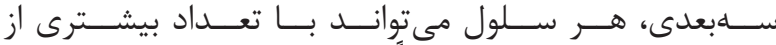

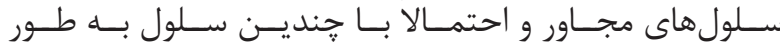

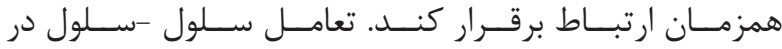

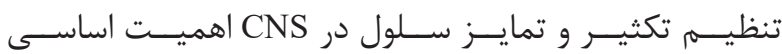

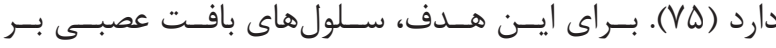

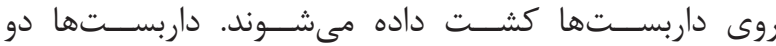

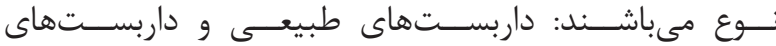

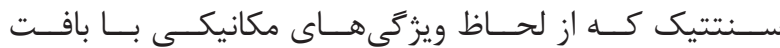

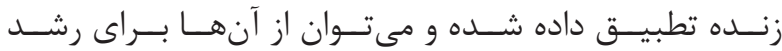

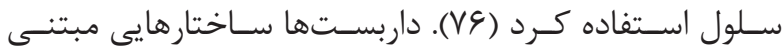

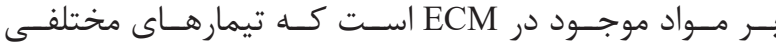

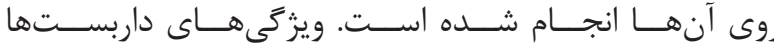




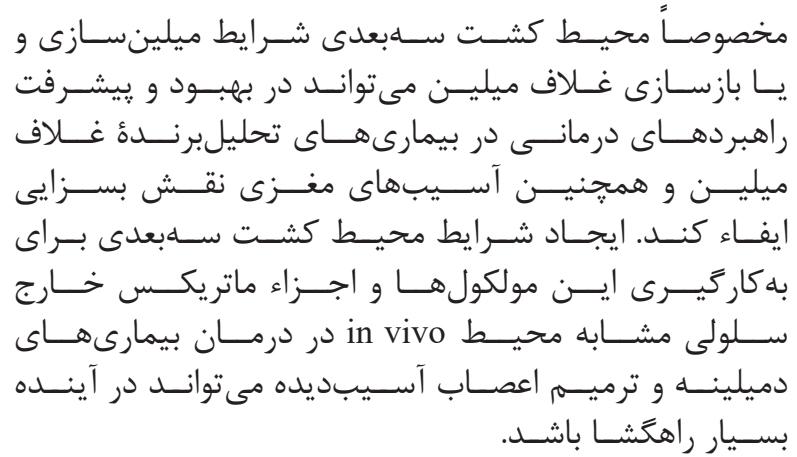

1. Williams A. Central nervous system regenerationwhere are we? QJM. 2014; 107(5): 335-9.

2. Chen Z-L, Strickland S. Laminin $\gamma 1$ is critical for schwann cell differentiation, axon myelination, and regeneration in the peripheral nerve. J Cell Biol. 2003; 163(4): 889-99.

3. Nave K-A, Werner HB. Myelination of the nervous system: mechanisms and functions. Annu Rev Cell Dev Biol. 2014; 30: 503-33.

4. Hall JE. Guyton and Hall textbook of medical physiology e-Book. 8th ed. Philadelphia: Elsevier Health Sciences. 2015.

5. Boullerne AI. The history of myelin. Exp Neurol. 2016; 283: 431-45.

6. Lau LW, Cua R, Keough MB, Haylock-Jacobs S, Yong VW. Pathophysiology of the brain extracellular matrix: a new target for remyelination. Nat Rev Neurosci. 2013; 14(10): 722-9.

7. Sherman LS, Back SA. A 'GAG'reflex prevents repair of the damaged CNS. Trends Neurosci. 2008; 31(1): 44-52.

8. Zhao C, Fancy SP, Franklin RJ, ffrench-Constant C. Up-regulation of oligodendrocyte precursor cell $\alpha \mathrm{V}$ integrin and its extracellular ligands during central nervous system remyelination. J Neurosci Res. 2009; 87(15): 3447-55.

9. Bercury KK, Macklin WB. Dynamics and mechanisms of CNS myelination. Dev Cell. 2015; 32(4): 447-58.

10. Garwood J, Garcion E, Dobbertin A, Heck N, Calco $\mathrm{V}$, Ffrench-Constant $\mathrm{C}$, et al. The extracellular matrix glycoprotein Tenascin-C is expressed by oligodendrocyte precursor cells and required for the regulation of maturation rate, survival and responsiveness to plateletderived growth factor. Eur J Neurosci. 2004; 20(10): 2524-40.

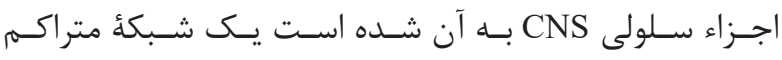

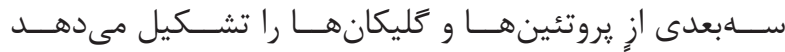

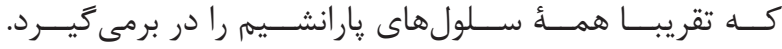

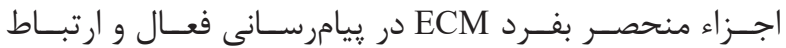

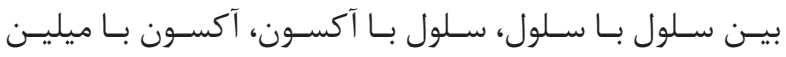

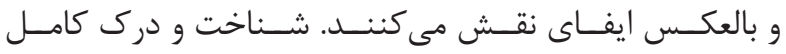

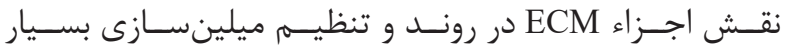

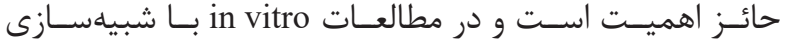

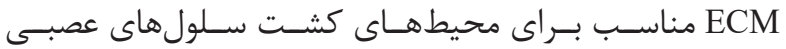

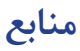

11. Bonneh-Barkay D, Wiley CA. Brain extracellular matrix in neurodegeneration. Brain Pathol. 2009; 19(4): 573-85.

12. Ghayour MB, Abdolmaleki A, Fereidoni M. Role of extracellular matrix in peripheral nerve regeneration process. RJMS. 2015; 22(135): 75-88.

13. Shen Y, Tenney AP, Busch SA, Horn KP, Cuascut FX, Liu K, et al. PTP $\sigma$ is a receptor for chondroitin sulfate proteoglycan, an inhibitor of neural regeneration. Science. 2009; 326(5952): 592-6.

14. Tang X, Davies JE, Davies SJ. Changes in distribution, cell associations, and protein expression levels of NG2, neurocan, phosphacan, brevican, versican V2, and Tenascin-C during acute to chronic maturation of spinal cord scar tissue. J Neurosci Res. 2003; 71(3): 427-44.

15. Haggerty AE, Marlow MM, Oudega M. Extracellular matrix components as therapeutics for spinal cord injury. Neurosci Lett. 2017; 652: 50-5.

16. Chun SJ, Rasband MN, Sidman RL, Habib AA, Vartanian T. Integrin-linked kinase is required for laminin-2-induced oligodendrocyte cell spreading and CNS myelination. J Cell Biol. 2003; 163(2): 397-408.

17. Pepper RE, Pitman KA, Cullen CL, Young KM. How do cells of the oligodendrocyte lineage affect neuronal circuits to influence motor function, memory and mood? Front Cell Neurosci. 2018; 12(399): 1-14.

18. Ahrendsen JT, Macklin W. Signaling mechanisms regulating myelination in the central nervous system. Neurosci Bull. 2013; 29(2): 199-215.

19. Eyermann C, Czaplinski K, Colognato H. Dystroglycan promotes filopodial formation and process branching in differentiating oligodendroglia. J Neurochem. 2012; 120(6): 928-47.

20. Colognato H, Galvin J, Wang Z, Relucio J, Nguyen 


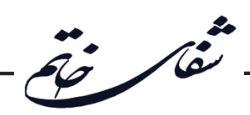

T, Harrison D, et al. Identification of dystroglycan as a second laminin receptor in oligodendrocytes, with a role in myelination. Development. 2007; 134(9): 1723-36.

21. Leiton CV, Aranmolate A, Eyermann C, Menezes MJ, Escobar-Hoyos LF, Husain S, et al. Laminin promotes metalloproteinase-mediated dystroglycan processing to regulate oligodendrocyte progenitor cell proliferation. J Neurochem. 2015; 135(3): 522-38.

22. Barros CS, Nguyen T, Spencer KS, Nishiyama A, Colognato H, Müller U. $\beta 1$ integrins are required for normal CNS myelination and promote AKT-dependent myelin outgrowth. Development. 2009; 136(16): 271724.

23. Baron W, Bijlard M, Nomden A, Jonge JC, Teunissen CE, Hoekstra D. Sulfatide-mediated control of extracellular matrix-dependent oligodendrocyte maturation. Glia. 2014; 62(6): 927-42.

24. Di Lullo GA, Sweeney SM, Körkkö J, Ala-Kokko L, San Antonio JD. Mapping the ligand-binding sites and disease-associated mutations on the most abundant protein in the human-type I collagen. J Biol Chem. 2002; 277(6): 4223-31.

25. Seppänen A, Autio-Harmainen H, Alafuzoff I, Särkioja T, Veijola J, Hurskainen T, et al. Collagen XVII is expressed in human CNS neurons. Matrix Biol. 2006; 25(3): $185-8$.

26. Suzuki H, Kanchiku T, Imajo Y, Yoshida Y, Nishida N, Gondo $\mathrm{T}$, et al. Artificial collagenfilament scaffold promotes axon regeneration and long tract reconstruction in a rat model of spinal cord transection. Med Mol Morphol. 2015; 48(4): 214-24.

27. Benarroch EE. Extracellular matrix in the CNS: dynamic structure and clinical correlations. Neurology. 2015; 85(16): 1417-27.

28. Hopkins AM, DeSimone E, Chwalek K, Kaplan DL. $3 \mathrm{D}$ in vitro modeling of the central nervous system. Prog Neurobiol. 2015; 125: 1-25.

29. Frantz C, Stewart KM, Weaver VM. The extracellular matrix at a glance. J Cell Sci. 2010; 123(24): 4195-200.

30. Wheeler NA, Fuss B. Extracellular cues influencing oligodendrocyte differentiation and (re)myelination. Exp Neurol. 2016; 283: 512-30.

31. Mayoral SR, Chan JR. The environment rules: spatiotemporal regulation of oligodendrocyte differentiation. Curr Opin Neurobiol. 2016; 39: 47-52.

32. Zeger M, Popken G, Zhang J, Xuan S, Lu QR,
Schwab $\mathrm{MH}$, et al. Insulin-like growth factor type 1 receptor signaling in the cells of oligodendrocyte lineage is required for normal in vivo oligodendrocyte development and myelination. Glia. 2007; 55(4): 400-11.

33. Baumann N, Pham-Dinh D. Biology of oligodendrocyte and myelin in the mammalian central nervous system. Physiol Rev. 2001; 81(2): 871-927.

34. Costales J, Kolevzon A. The therapeutic potential of insulin-like growth factor- 1 in central nervous system disorders. Neurosci Biobehav Rev. 2016; 63: 207-22.

35. Ye P, Li L, Richards RG, DiAugustine RP, D'Ercole AJ. Myelination is altered in insulin-like growth factor-I null mutant mice. J Neurosci. 2002; 22(14): 6041-51.

36. Galvin J, Eyermann C, Colognato H. Dystroglycan modulates the ability of insulin-like growth factor-1 to promote oligodendrocyte differentiation. J Neurosci Res. 2010; 88(15): 3295-307.

37. Becker-Catania SG, Nelson JK, Olivares S, Chen SJ, DeVries GH. Oligodendrocyte progenitor cells proliferate and survive in an immature state following treatment with an axolemma-enriched fraction. ASN Neuro. 2011; 3(1): e00053.

38. Ratzka A, Baron O, Grothe C. FGF-2 deficiency does not influence FGF ligand and receptor expression during development of the nigrostriatal system. PLoS One. 2011; 6(8): e23564.

39. Bryant M, Marta C, Kim F, Bansal R. Phosphorylation and lipid raft association of fibroblast growth factor receptor-2 in oligodendrocytes. Glia. 2009; 57(9): 935-46.

40. Caggiula M, Batocchi A, Frisullo G, Angelucci F, Patanella A, Sancricca C, et al. Neurotrophic factors and clinical recovery in relapsing-remitting multiple sclerosis. Scand J Immunol. 2005; 62(2): 176-82.

41. Shirazi A, Golab F, Sanadgol N, Barati M, Salehi RM, Vahabzadeh G, et al. Evaluation of the neurotrophic factors in animal model of myelin destruction induced by cuprizone in C57bl/6 mice. Shefaye Khatam. 2016; 4(2): 47-54.

42. Fang M, He D, Zhang F, Hu Z, Yang J, Jiang H, et al. Antineuroinflammatory and neurotrophic effects of CNTF and C16 peptide in an acute experimental autoimmune encephalomyelitis rat model. Front Neuroanat. 2013; 7: 44.

43. Stankoff B, Aigrot M-S, Noël F, Wattilliaux A, Zalc B, Lubetzki C. Ciliary neurotrophic factor (CNTF) enhances myelin formation: a novel role for $\mathrm{CNTF}$ and CNTF-related molecules. J Neurosci. 2002; 22(21): 
9221-7.

44. Mei L, Nave K-A. Neuregulin-ERBB signaling in the nervous system and neuropsychiatric diseases. Neuron. 2014; 83(1): 27-49.

45. Tomassy GS, Dershowitz LB, Arlotta P. Diversity matters: a revised guide to myelination. Trends Cell Biol. 2016; 26(2): 135-47.

46. Kim JY, Sun Q, Oglesbee M, Yoon SO. The role of ErbB2 signaling in the onset of terminal differentiation of oligodendrocytes in vivo. J Neurosci. 2003; 23(13): 5561-71.

47. Taveggia C, Thaker P, Petrylak A, Caporaso GL, Toews A, Falls DL, et al. Type III neuregulin-1 promotes oligodendrocyte myelination. Glia. 2008; 56(3): 284-93.

48. Reinhard J, Roll L, Faissner A. Tenascins in retinal and optic nerve neurodegeneration. Front Integr Neurosci. 2017; 11: 30. doi: 10.3389/fnint.2017.00030.

49. Quraishe S, Forbes LH, Andrews MR. The extracellular environment of the CNS: influence on plasticity, sprouting, and axonal regeneration after spinal cord injury. Neural Plast. 2018; 2018.

50. Becker T, Anliker B, Becker CG, Taylor J, Schachner M, Meyer RL, et al. Tenascin-R inhibits regrowth of optic fibers in vitro and persists in the optic nerve of mice after injury. Glia. 2000; 29(4): 330-46.

51. Garcion E, Faissner A. Knockout mice reveal a contribution of the extracellular matrix molecule Tenascin-C to neural precursor proliferation and migration. Development. 2001; 128(13): 2485-96.

52. Czopka T, von Holst A, Faissner A. Regulatory mechanisms that mediate tenascin C-dependent inhibition of oligodendrocyte precursor differentiation. J Neurosci. 2010; 30(37): 12310-22.

53. Perez MJ, Fernandez N, Pasquini JM. Oligodendrocyte differentiation and signaling after transferrin internalization: a mechanism of action. Exp Neurol. 2013; 248: 262-74.

54. Motavaf M, Sadeghizadeh M, Javan M. Attempts to overcome remyelination failure: toward opening new therapeutic avenues for multiple sclerosis. Cell Mol Neurobiol. 2017; 37(8): 1335-48.

55. Anlar B, Gunel-Ozcan A. Tenascin-R: role in the central nervous system. Int J Biochem Cell Biol. 2012; 44(9): 1385-9.

56. Garcia C, Paez P, Davio C, Soto EF, Pasquini JM.
Apotransferrin induces cAMP/CREB pathway and cell cycle exit in immature oligodendroglial cells. J Neurosci Res. 2004; 78(3): 338-46.

57. Marziali L, Garcia C, Pasquini J. Transferrin and thyroid hormone converge in the control of myelinogenesis. Exp Neurol. 2015; 265: 129-41.

58. Bernard F, Moreau-Fauvarque C, Heitz-Marchaland C, Zagar Y, Dumas L, Fouquet S, et al. Role of transmembrane semaphorin Sema6A in oligodendrocyte differentiation and myelination. Glia. 2012; 60(10): 1590-604.

59. Alto LT, Terman JR. Semaphorins and their signaling mechanisms. Semaphorin Signaling: Springer; 2017. p. $1-25$.

60. Cohen RI, Rottkamp DM, Maric D, Barker JL, Hudson LD. A role for semaphorins and neuropilins in oligodendrocyte guidance. J Neurochem. 2003; 85(5): 1262-78.

61. Zhang H-L, Wang J, Tang L. Sema4D knockdown in oligodendrocytes promotes functional recovery after spinal cord injury. Cell Biochem Biophys. 2014; 68(3): 489-96.

62. Yamaguchi W, Tamai R, Kageura M, Furuyama $\mathrm{T}$, Inagaki S. Sema4D as an inhibitory regulator in oligodendrocyte development. Mol Cell Neurosci. 2012; 49(3): 290-9.

63. Syed YA, Hand E, Möbius W, Zhao C, Hofer M, Nave KA, et al. Inhibition of CNS remyelination by the presence of semaphorin 3A. J Neurosci. 2011; 31(10): 3719-28.

64. Dyck S, Kataria H, Alizadeh A, Santhosh KT, Lang B, Silver J, et al. Perturbing chondroitin sulfate proteoglycan signaling through LAR and PTP $\sigma$ receptors promotes a beneficial inflammatory response following spinal cord injury. J Neuroinflammation. 2018; 15(1): 90. doi: 10.1186/s12974-018-1128-2.

65. Phillips JB, Bunting SC, Hall SM, Brown RA. Neural tissue engineering: a self-organizing collagen guidance conduit. Tissue Eng. 2005; 11(9-10): 1611-7.

66. Yiu G, He Z. Glial inhibition of CNS axon regeneration. Nat Rev Neurosci. 2006; 7(8): 617-27.

67. Lau LW, Keough MB, Haylock-Jacobs S, Cua R, Doring A, Sloka S, et al. Chondroitin sulfate proteoglycans in demyelinated lesions impair remyelination. Ann Neurol. 2012; 72(3): 419-32.

68. Siebert JR, Osterhout DJ. The inhibitory effects of 


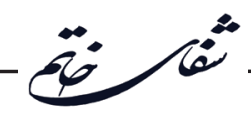

chondroitin sulfate proteoglycans on oligodendrocytes. J Neurochem. 2011; 119(1): 176-88.

69. Karimi-Abdolrezaee S, Schut D, Wang J, Fehlings MG. Chondroitinase and growth factors enhance activation and oligodendrocyte differentiation of endogenous neural precursor cells after spinal cord injury. PLoS One. 2012; 7(5): e37589.

70. Siebert JR, Stelzner DJ, Osterhout DJ. Chondroitinase treatment following spinal contusion injury increases migration of oligodendrocyte progenitor cells. Exp Neurol. 2011; 231(1): 19-29.

71. Keough MB, Rogers JA, Zhang P, Jensen SK, Stephenson EL, Chen T, et al. An inhibitor of chondroitin sulfate proteoglycan synthesis promotes central nervous system remyelination. Nat Commun. 2016; 7: 11312. doi: $10.1038 /$ ncomms 11312 .

72. McMurran CE, Kodali S, Young A, Franklin RJ. Clinical implications of myelin regeneration in the central nervous system. Expert Rev Neurother. 2018; 18(2): 111-23.

73. Khojasteh MR, Shariat Razavi A, Javadzadeh A, Gorji A, Sahab Negah S. Cell therapy: A therapeutic option for multiple sclerosis. Shefaye Khatam. 2018; 6(3): 52-68.

74. Pourabdolhossein F, Mozafari S, Javan M, Mirnajafizadeh SJ, Ahmadiani A. Electrophysiological and histological study of lysolecithin-induced local demyelination in adult mice optic chiasm. Physiol Pharmacol. 2011; 14(4): 324-36.

75. Egawa N, Shindo A, Liang AC, Du Y, Xing C, Lo $\mathrm{EK}$, et al. A novel three-dimensional culture system for oligodendrocyte precursor cells. Stem Cells Dev. 2017; 26(14): 1078-85.

76. Mohammad S-S, Sahab NS, Khaksar Z, Kazemi H, Aligholi H. Laminin position as one of the important components of the extracellular matrix in tissue engineering of nervous system. Shefaye Khatam. 2014;
2(1): $69-74$.

77. Dutta RC, Dutta AK. Cell-interactive 3D-scaffold; advances and applications. Biotechnol Adv. 2009; 27(4): 334-9.

78. Phillips JB, King VR, Ward Z, Porter RA, Priestley JV, Brown RA. Fluid shear in viscous fibronectin gels allows aggregation of fibrous materials for CNS tissue engineering. Biomaterials. 2004; 25(14): 2769-79.

79. Sahab NS, Mohammad SS, Kazemi H, Modarres MSM, Aligholi H. Effect of injured brain extract on proliferation of neural stem cells cultured in 3-dimensional environment. Shefaye Khatam. 2015; 3(1): 49-56.

80. Espinosa-Hoyos D, Jagielska A, Homan KA, Du H, Busbee T, Anderson DG, et al. Engineered 3D-printed artificial axons. Sci Rep. 2018; 8(1): 478. doi: 10.1038/ s41598-017-18744-6.

81. Russell LN, Lampe KJ. Engineering biomaterials to influence oligodendroglial growth, maturation, and myelin production. Cells Tissues Organs. 2016; 202(12): $85-101$.

82. Russell LN, Lampe KJ. Oligodendrocyte precursor cell viability, proliferation, and morphology is dependent on mesh size and storage modulus in 3D poly (ethylene glycol)-based hydrogels. ACS Biomater Sci Eng. 2017; 3(12): 3459-68.

83. Barati DP, Roshanaei K, Sahab NS, Aligholi H, Alipour F, Darvishi M. Functional role of natural and synthetic scaffolds in tissue engineering of central nervous system. Shefaye Khatam. 2016; 4(1): 77-92.

84. Cheung H-Y, Lau K-T, Lu T-P, Hui D. A critical review on polymer-based bio-engineered materials for scaffold development. Composites Part B: Engineering. 2007; 38(3): 291-300.

85. Ravi M, Paramesh V, Kaviya S, Anuradha E, Solomon FP. 3D cell culture systems: advantages and applications. J Cell Physiol. 2015; 230(1): 16-26. 